OPEN ACCESS

Edited by:

Haiyang Tang,

University of Arizona, United States

Reviewed by:

Pritesh Jain,

University of California, San Diego,

United States

Stephen C. Kolwicz Jr,

Ursinus College, United States

*Correspondence:

Haitao Shen

shenht@sj-hospital.org

Specialty section:

This article was submitted to Cardiovascular Metabolism,

a section of the journal

Frontiers in Cardiovascular Medicine

Received: 10 July 2021

Accepted: 27 August 2021

Published: 20 September 2021

Citation:

Yin $Y$ and Shen $H$ (2021) Advances in

Cardiotoxicity Induced by Altered

Mitochondrial Dynamics and

Mitophagy.

Front. Cardiovasc. Med. 8:739095.

doi: $10.3389 / f c v m .2021 .739095$

\section{Advances in Cardiotoxicity Induced by Altered Mitochondrial Dynamics and Mitophagy}

\author{
Yiyuan Yin and Haitao Shen* \\ Department of Emergency Medicine, ShengJing Hospital of China Medical University, Shenyang, China
}

Mitochondria are the most abundant organelles in cardiac cells, and are essential to maintain the normal cardiac function, which requires mitochondrial dynamics and mitophagy to ensure the stability of mitochondrial quantity and quality. When mitochondria are affected by continuous injury factors, the balance between mitochondrial dynamics and mitophagy is broken. Aging and damaged mitochondria cannot be completely removed in cardiac cells, resulting in energy supply disorder and accumulation of toxic substances in cardiac cells, resulting in cardiac damage and cardiotoxicity. This paper summarizes the specific underlying mechanisms by which various adverse factors interfere with mitochondrial dynamics and mitophagy to produce cardiotoxicity and emphasizes the crucial role of oxidative stress in mitophagy. This review aims to provide fresh ideas for the prevention and treatment of cardiotoxicity induced by altered mitochondrial dynamics and mitophagy.

Keywords: mitochondrial dynamics, cardiotoxicity, mitophagy, mitochondrial fission, mitochondrial fusion

\section{INTRODUCTION}

As the body's "power plant," heart is the body's largest oxygen and energy consumption organ. Therefore, mitochondria, as the core organelles of oxidative phosphorylation, play an important role in maintaining cardiac homeostasis. Under normal conditions, cardiac cells regulate the dynamic balance of mitochondria through a variety of signal pathways, remove damaged mitochondria through the process of mitochondrial fission, fusion and autophagy, and maintain the normal cardiac function. However, injury factors such as hypoxia, oxidative stress, poisoning, and hyperglycemia can cause abnormalities in mitochondrial dynamics and mitophagy, resulting in cardiotoxicity. Therefore, interventional treatment for different injury factors is of great significance for improving cardiotoxicity induced by altered mitochondrial dynamics and mitophagy.

\section{CONCEPT OF MITOCHONDRIAL DYNAMICS AND MITOPHAGY}

Mitochondria are critical organelles of eclectic cells and can reach $25-35 \%$ of cell volume (1-3). They have a phospholipid bimolecular membrane structure and play a crucial role in maintaining normal functionality in cells and metabolizing steady state. Moreover, they are also the primary locations for the oxidative metabolism of cells. Also, mitochondria have a mediated effect on cell proliferation or apoptosis, regulation of nuclear gene expression, 
and innate immunity $(4,5)$. Under normal physiological conditions, mitochondria produce ATP through the tricarboxylic acid cycle to meet the energy needs of the heart (6-8). It is not only the power plant of the cell, but also the center of signal transmission including calcium homeostasis $(9,10)$, which ensure the normal operation of the mitochondrial electron transport chain to maintain the normal cardiac function (11, 12). In the electron transport chain, premature leakage of electrons will lead to the production of physiological reactive oxygen species (ROS), and a small amount of ROS can be decomposed by superoxide dismutase (SOD) and glutathione (GSH) in the mitochondria $(9,10,13)$. When the mitochondria is in an abnormal state, the tricarboxylic acid cycle and calcium homeostasis are destroyed, and the mitochondrial membrane potential dissipation in turn leads to the disorder of the electron transport chain and the accumulation of ROS (14, 15). The original mitochondrial quality of cardiac cells cannot maintain the normal function of cardiac cells, resulting in cardiac dysfunction and cardiotoxicity $(6,16,17)$.

Although mitochondria are usually described as independent organelles, they actually form a dynamic equilibrium network maintained by mitochondrial dynamics, which is essential for maintaining normal cell metabolism. In mitochondrial structures, the outer mitochondrial membranes (OMM) comprises a relatively smooth lipid double layer, and the inner mitochondrial membrane (IMM) folds inwards to form a structure called argon (18). The fission of membranes and outer membranes in mitochondria is a critical event in mitochondrial fission; it is a process that divides a single mitochondrion into two mitochondria, guided by a dynamin-related protein 1 (DRP1) (19). Mitochondrial fusion is divided into outer membrane fusion and endometrial fusion, the balance of which determines the connectivity of the network (20).

Mitophagy is the process that identifies damaged mitochondria in cells, which in turn binds to autophagyrelated proteins to create autophagic small bodies. These bodies are degraded by fusion with lysosomes (21). Generally, mitochondria are abundant in cardiac cells, making the cardiac cells more sensitive to alterations in mitochondrial functionality (22). Under normal circumstances, a certain mitophagy level promptly removes damage to aging mitochondria and metabolic toxic substances, promotes mitochondrial renewal, and ensures the survival of cells (23-25).

\section{THE PHYSIOLOGICAL STATE OF MITOCHONDRIAL DYNAMICS AND MITOPHAGY}

Cardiotoxicity is caused by altered mitochondrial dynamics and mitophagy $(26,27)$. The cardiac cells can remove dysfunctional mitochondria through mitochondrial fission, fusion, and autophagy. The process has a direct regulatory effect on the quantity and quality of the cardiac mitochondria. Thus, it ensures the stability of the inner environment of cardiac cells (28-32). Under normal physiological conditions, mitochondria are constantly updated to sustain healthy cardiac functionality. Moreover, it can promote the formation of new mitochondria and maintain the cardiac continuous contraction. At this stage, the cardiac can promptly remove damaged mitochondria through fission, fusion, and autophagy, and facilitate the recovery of effective cellular components, such as proteins, deoxyribonucleic acid (DNA), etc., to ensure the normal metabolism of updated cells, thus compensate to ensure the nominal function of mitochondria to maintain the cardiac continuous contraction state (33).

It is generally believed that fission and fusion are carried out at the same time and are dynamically balanced, and fission is often regarded as a prerequisite for mitophagy (34-37). Parkin, the key protein of mitophagy, can induce ubiquitination or degradation of MFN1/2, thereby inhibiting mitochondrial fusion $(38,39)$. The significance of mitophagy for fusion is that when damaged mitochondria fuse with healthy mitochondria, a larger damaged mitochondria will be formed, which can activate mitophagy and maintain mitochondrial homeostasis (34, 40-42). In mitochondrial fission, fusion and mitophagy, mitochondrial autophagy plays a central role (34).

\section{Mitochondrial Fission}

Mitochondrial fission is divided into the fission of membranes and outer membranes in mitochondria and is regulated by DRP1 $(43,44)$. DRP1 is classified as a homologous protein of guanosine triphosphate (GTP) hydrolyzed enzyme (GTPase) power protein. It has an active role in endocytosis and is a key regulatory factor in mitochondrial fission, primarily located in cell pulp $(20,45,46)$.

The serine 637 (S637) phosphorylation of DRP1 inhibits the translocation of mitochondria DRP1 and its GTPase activity. Meanwhile, serine 616 (S616) phosphorylation elevates the DRP1 activity, which splits the mitochondria. During the fission process, mitochondrial fission 1 (FIS1) protein, mitochondrial fission factor (MFF), $49 \mathrm{kDa}$ mitochondrial dynamic protein (MiD49), and $51 \mathrm{kDa}$ mitochondrial kinetic protein (MiD51) induce DRP1 phosphorylation to recruit DRP1 into the mitochondrial outer membrane. Afterward, the DRP1 oligopoly reaction at the fission point of the OMM self-assembles to create a spiral structure. It forms a cleavage ring that shrinks and shears the mitochondrial outer and inner membranes and breaking the mitochondria (47-54). Notably, FIS1 is distributed throughout the outer membrane, while MFF is dotted, showing a stronger interaction with DRP1 than FIS1. FIS1 and MFF can independently promote the collection and oligopoly of the mitochondrial outer membrane, yet, MFF plays a more critical role. Besides, in the absence of MFF and FIS1, MiD49 and MiD51 can recruit DRP1 to the mitochondria (49).

Furthermore, cyclase-associated protein (CAP) are recently discovered split-promoting proteins that induce the oligomerization of DRP1 and the expression of FIS1, which promotes DRP1-mediated mitochondrial fission (55).

\section{Mitochondrial Fusion}

Mitochondrial fusion is divided into outer membrane fusion and endometrial fusion. It is regulated by a variety of proteins, including mitofusin (MFN) in the outer membrane of mitochondria and optic atrophy protein 1 (OPA1) (44, 
45, 49, 51, 56-61). Among them, mitofusin 1 (MFN1) and mitofusin 2 (MFN2) regulate mitochondrial outer membrane fusion. MFN1 positioned mitochondria and MFN2 positioned mitochondria and endoplasmic reticulum. MFN1 and MFN2 form a stable homologous dimer through their GTPase domain. Next, hydrolyzed GTP and the outer membrane of the two mitochondria are combined and fused, which is critical for outer membrane fusion $(49,52,54,56)$.

The OPA1 regulates the fusion of the IMM. OPA1 is treated with mitochondrial processing peptide (MPP) enzyme to produce a long-form OPA1 (L-OPA1) of membrane binding, and then positioned as intermembrane space AAA (i-AAA) protease in the membrane of the mitochondria IMM peptide enzymes and mitochondrial AAA (m-AAA) protease are further cut into short -form OPA1 (S-OPA1). Afterward, the mitochondrial membranes are arranged into two layers of film while maintaining the fidelity of the mitochondrial crucible structure and promoting endometrial fusion $(49,58,62)$.

\section{Mitophagy}

Mitophagy is an autophagy process that is regulated by several mechanisms and protein molecules. However, it is different than ordinary autophagy and is highly selective $(63,64)$. Presently, three major pathways can induce and activate mitophagy: PTEN-induced kinase 1 (PINK1)-Parkin signaling pathway, BCL2 interacting protein 3 (BNIP3)/NIP3-like protein X (NIX) pathway, and the FUN14 domain containing 1 (FUNDC1) signaling pathway. Out of the three, the PINK1-Parkin signaling pathway is the most characteristic and significant autophagy pathway (65-67). In mitophagy, different pathways cooperate and coordinate to sustain the normal functionality in cells.

\section{The PINK1-Parkin Signaling Pathway}

PINK1 is a mitochondrial serine-threonine protein kinase. When the mitochondrial membrane potential decreases, the PINK1-Parkin signaling pathway PINK1 aggregates in the mitochondrial membrane's outer membrane and activates Parkin on damaged mitochondria (68-76). Generally, PINK1 is less expressed. It enters the mitochondria, anchors the mitochondrial intima through the mediation of outer membrane-related proteins. Under external stimulation or pathological conditions, mitochondrial depolarization can cause PINK1 translocation to mitochondria's outer membrane. Afterward, it catalyzes ubiquitin phosphorylation to activate the Parkin receptor binding Parkin and initiate mitophagy (30, 70, 77-85). Moreover, the PINK1Parkin pathway is also the primary mechanism of Zinc induced mitophagy (86).

\section{BNIP3/NIX Pathway}

BNIP3 (also known as NIX) is a member of the Bcl-2 protein family. It is a form of a mitochondrial outer membrane protein with a biphasic effect. The phosphorylation of their microtubuleassociated protein $1 \mathrm{~A} / 1 \mathrm{~B}$-light chain 3 (LC3)-interacting region (LIR) binds to LC3-phosphatidylethanolamine conjugate light chain 3 (LC3II), which is involved in mitophagy and plays a significant role in myocardial mitochondrial regeneration (24, 87-89). The hypoxia inducible factor 1 subunit alpha (HIF-1 $\alpha$ ) can bind to the BNIP3 promoter to induce BNIP3, and BNIP3 expression can also promote PINK1 translocation, and then induce mitophagy (90). Reportedly, the cardiac dual-specificity phosphatase-1 (DUSP1) also induces BNIP3 expression and promotes mitophagy (91).

\section{FUNDC1 Signaling Pathway}

The FUNDC1 is a highly conserved mitochondrial outer membrane protein. Similar to BNIP3/NIX, it directly interacts with LC3 through the $\mathrm{N}$ end, mediating hypoxia-induced mitophagy, which is widely expressed in various cells, tissues, and organs, particularly heart $(63,79,88,90,92,93)$. Under normal oxygen conditions, FUNDC1 phosphorylated by semi refined carrageenan (SRC) kinases and Casein kinase II (CK2) decreases their affinity to LC3, which effectively inhibits mitophagy. FUNDC1 was dephosphorylated by serine 13-position phosphatase, such as PGAM family member 5 (PGAM5), triggering its association with LC3, thereby enhancing mitophagy $(23,88,93)$.

\section{Biogenesis}

Mitochondrial biogenesis is also considered to be an important factor in maintaining mitochondrial homeostasis. It is a complex process involving the synthesis of mitochondrial inner and outer membranes and mitochondrial-encoded proteins, the synthesis and input of mitochondrial-encoded proteins, and the replication of mitochondrial DNA (mtDNA) (94-97), which is mainly regulated by PPARG Coactivator 1 Alpha (PGC-1 $\alpha$ ) and Nuclear Respiratory Factor 1 (NRF1), and can be defined as "the process of producing new components of the mitochondrial network" (98-100). Some scholars evaluate the biogenesis of mitochondria by measuring the rate of mitochondrial protein synthesis. Mitochondrial biogenesis and mitophagy coordinately regulate the molecular mechanism of mitochondrial homeostasis (101104). On the one hand, the process of mitochondrial biogenesis is accompanied by mitophagy, on the other hand, abnormal mitophagy can feedback and inhibit mitochondrial biogenesis, and the PGC-1 $\alpha$-NRF1-FUNDC1 pathway plays a key role in it, cooperating to maintain the quality and quantity of mitochondria $(96,97,105,106)$.

\section{THE PATHOPHYSIOLOGICAL STATE OF MITOCHONDRIAL DYNAMICS AND MITOPHAGY}

When cardiac cells are stimulated by mechanical traction, ischemia-reperfusion injury, and oxidative stress, they can cause changes in the shape, structure and function of the heart (107-110). Multiple signal pathways are activated when the heart is stimulated by pathogenic factors, such as mitogenactivated protein kinase signaling pathway, calcineurin (CaN) signaling pathways, protein kinase A signaling pathways and angiotensin type I receptors cause calcium homeostasis to be destroyed and calcium overload, which ultimately leads to cardiac pathophysiological changes (111-114). When excessive or continuous stress acts on the heart, the mitochondrial 
energy metabolism function and quality control system are seriously disturbed, which exceeds the self-regulation range of mitochondrial dynamics and mitophagy. On the one hand, it causes the energy metabolism of cardiac cells to become impaired, on the other hand, the mtDNA and ROS released by damaged mitochondria accumulate to reach a toxic concentration, which together lead to cardiotoxicity $(25,66,115-117)$, the process of cardiotoxicity caused by different injury factors is shown in Figure 1. Cardiotoxicity refers to cardiac damage caused by excessive accumulation of endogenous or exogenous substances to reach a toxic concentration (118). Generally speaking, cardiotoxicity can cause cardiac electrophysiological dysfunction or myocardial damage (119). Moreover, mitochondrial dynamics play a vital role in the onset of nervous system diseases, implying that mitochondrial dynamics disorders may have damaging effects on cardiac neuronal cells (120).

In addition, among smoking and obesity people, the cardiovascular morbidity has increased significantly (121-126). It has been reported that smoking and obesity can cause abnormal mitochondrial dynamics and mitophagy (127-131). Therefore, smoking and obesity may also lead to mitochondrial damage, which in turn causes cardiac dysfunction, leading to cardiotoxicity.

\section{Hypoxia}

Generally, hypoxia refers to any kind of physiological oxygen deficiency or tissue oxygen demand deficiency state and the integration of local responses defines hypoxia as a paradigm of reactions affecting the entire body $(86,132,133)$. Studies have shown that inhibiting the breathing of rats caused obvious cardiotoxicity $(79,134-138)$.

\section{Mitochondrial Fission, Fusion, and Hypoxia}

During mitochondrial fission, lack of oxygen can increase the production of 4-hydroxyethyl ether (4-HNE) to promote the S616 phosphorylation of DRP1 to induce mitochondrial fission. Besides, in the presence of histone deacetylase 6 (HDAC6), hypoxia can promote mitochondrial fusion by inducing the binding of HDAC6 with MFN2, causing mitochondrial dysfunction (139-141).

\section{Mitophagy and Hypoxia}

Hypoxia can be specifically activated by FUNDC1; under normal conditions, FUNDC1 is highly conserved and stable in mitochondria's outer membrane. During hypoxia, it is FUNDC1 dephosphorylated by 13 phosphatases (such as PGAM5) of serine, triggering its binding to LC3 and improving mitophagy activity. It removes damaged mitochondria $(23,79,88,92,93$, 142-144). Hypoxia can activate poly (ADP-ribose) polymerase (PARP), promoting mitophagy by regulating mitochondrial membrane potential and inducing cardiomyocyte apoptosis, ROS is central for PARP mediated mitochondrial membrane potential $(\Delta \Psi \mathrm{m})$ decline, and inhibited PARP can reduce the production after injury (80). Moreover, the activation of FUNDC1 is vital in platelet aggregation. Past studies have demonstrated that lacking the FUNDC1 gene can make the mitochondrial function of blood platelet disordered. In long-term hypoxia, it will eventually form a microthrombus and lead to cardiac microvascular structure destruction $(79,145)$.

\section{Oxidative Stress}

Oxidative stress (OS) is a state of imbalance between oxidation and antioxidant effect in the body. It produces several destructive products, such as ROS, which has an adverse impact on the body and is often considered to be a crucial factor that leads to aging and disease $(146,147)$. OS is caused by the imbalance between ROS and endogenous antioxidants in response to injury, which can lead to cardiotoxicity (148). ROS is a collective common term that includes highly oxidative radicals such as hydroxyl (OH-) and superoxide (O2•-) radicals, and non-radical species such as hydrogen peroxide (H2O2) (149151). Antioxidants in the mitochondria, such as superoxide dismutase (SOD) and glutathione (GSH), will rapidly degrade or sequester O2·-, thereby reducing reactivity (152-154). Due to the high concentration of mitochondria in myocardial tissue, reduced mitochondrial antioxidant capacity results in cardiac dysfunction (155-157). In addition, ROS is involved in a series of vascular diseases associated with the functional properties of the endothelial cell barrier (158-160).

Reportedly, ROS can significantly promote the activity of DRP1 to increase the mitochondrial fission frequency, resulting in mitochondrial dysfunction. Oxidative stress can significantly increase the expression of WD repeat domain 26 (WDR26) protein, which is a critical medium for PINK1-Parkin signaling pathways to induce cell mitophagy and depolarize mitochondria by elevating the mitochondrial membrane potential, causing PINK1 to transpose, which in turn catalyzes ubiquitin phosphorylation to activate the Parkin receptor (70, 78-80, 161). Parkin is dependent on p53, it triggers mitophagy through autophagy small body lysosome pathways and then degrades through autophagy-lysosome pathways. Moreover, oxidative stress could also lead to an extended opening time for mitochondrial permeability transition pore (mPTP), releasing apoptosis factors such as cytochrome c into the matrix, damaging cells (162-164). Meanwhile, ROS activates multiple inflammatory pathways such as NLR family pyrin domain containing 3 (NLRP3)-mediated inflammatory responses. And the inhibition of mitophagy further aggravates these inflammatory responses and exacerbates damage (165). During myocardial ischemic re-perfusion injury (MIRI), the cell ischemia hypoxia activates PINK1/Parkin-mediated mitophagy and then removes the defective mitochondria. Afterward, restores the intracellular steady-state to offset the damage inflicted by hypoxia. In the case where Parkin is lacking, it will further aggravate ischemia re-perfusion damage and inflict damage to the heart $(78,166-170)$. Uncoupling protein 2 (UCP2) and vitamin D interferes with abnormal mitophagy to protect the damaged cardiac from ischemic re-injection $(171,172)$. Moreover, oxidative stress reactions can also activate mitophagy through BNIP3/NIX and ROS promotes BNIP3 expression by activating the HIF- $1 \alpha$, which subsequentially induces mitophagy $(89,90)$. Reportedly, the oxidative stress response is a crucial cause of mitophagy disorders in diabetic 


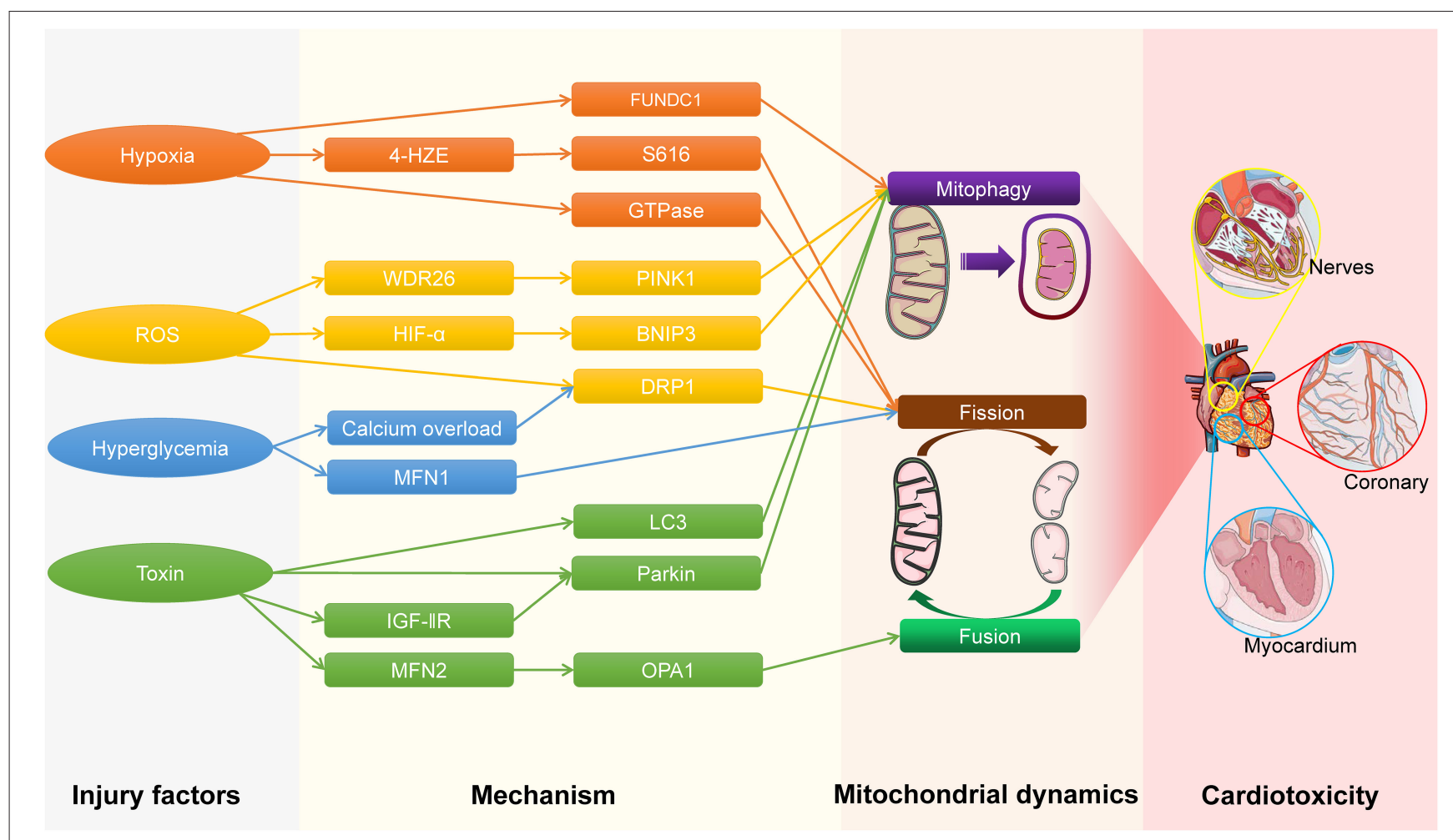

FIGURE 1 | The process of cardiotoxicity caused by different injury factors.

patients (24). In addition, membrane associated Ring- $\mathrm{CH}-$ Type Finger 5 (MARCHF5) and cellular communication network factor 1 (CCN1/Cyr61) are protein molecules located in the mitochondrial outer membrane, these proteins also play a vital role in the autophagy process of mitochondria, reducing expression during oxidative stress, and further inhibits mitophagy $(173,174)$.

\section{Hyperglycemia}

Studies have shown that hyperglycemia can increase the opening of MPTP by causing mitochondrial rupture and stimulating the generation of ROS, leading to the release of cytochrome $\mathrm{c}$ into the cytoplasm to activate the NLRP3 inflammasome (175-177). Subsequently, NLRP3 activates downstream nuclear factors to cause the release of inflammatory factors such as TNF- $\alpha$ and IL-6 further promotes the occurrence of inflammation, which wellexplains the pathogenesis of diabetic cardiomyopathy (178-180).

Hyperglycemia causes calcium overload by activating the ORAI calcium release-activated calcium modulator 1 (ORAI1) channel-mediated $\mathrm{Ca}^{2+}$ internal flow pathway. It would induce S616 phosphorylation to further advance the expression of DRP1 and inhibit the MFN1 gene expression, as well as promote mitochondria fission, resulting in mitochondrial dysfunction (53, 181, 182). Moreover, protein kinase A activity is significantly inhibited at low glucose levels, enhancing the positioning capacity of DRP1 on the outer membrane of the mitochondria, which significantly increases the rate of mitochondrial fission (183). Past studies have established that hunger or reduced insulin signals are a strong trigger for autophagy $(92,184,185)$. Hyperglycemia can induce myocardial mitochondria division but inhibit mitophagy, causing the accumulation of functionally impaired mitochondria $(57,186,187)$. Additionally, DRP1 and ROS have mutually reinforcing associations (188). As a result, oxidative stress reactions increase and ROS accumulates during hyperglycemia conditions, which further damages cardiac cells $(24,189)$.

\section{Poisoning}

Poisoning refers to the systemic damage caused by the poisoning amount of harmful substances after entering the human body. Cardiotoxicity caused by drugs is divided into type I cardiotoxicity and type II cardiotoxicity (190-193). Among them, type I cardiotoxicity is associated with irreversible cardiac cell injury and is typically caused by anthracyclines and conventional chemotherapeutic agents, such as doxorubicin (DOX), daunorubicin, taxane and so on (194-196). Type II cardiotoxicity, associated with reversible myocardial dysfunction, is generally caused by biologicals and targeted drugs, such as trastuzumab, pertuzumab, azidothymidine, sumatinib, cloflupine, and cocaine, ethanol, etc $(197,198)$. The above-mentioned drugs can cause cardiotoxicity by interfering with mitochondrial dynamics and mitophagy, and ROS plays an important role in this process $(26,199-202)$. Studies have shown that anthracyclines such as doxorubicin and daunorubicin accumulate in the heart by binding to cardiolipin in the inner mitochondrial membrane (198). Anthracyclines binds with high 
affinity to the mitochondrial phospholipid cardiolipin, inhibits its function, stimulates ROS production, inhibits oxidative phosphorylation, and causes mitochondrial DNA damage. These events result in mitochondrial defects, leading to the opening of mPTP and the activation of cell death pathways, which precipitate myocardial dysfunction $(27,203,204)$. In addition, recent experimental studies have found mitochondrial iron accumulation following doxorubicin to be the mediator of doxorubicin cardiotoxicity from redox cycling and oxidative injury. $\mathrm{ABCB} 8$, a mitochondrial transport protein facilitates the export of iron from the mitochondria. Doxorubicin reduces $\mathrm{ABCB} 8$ transporter in the mitochondria. Overexpression of ABCB8 protein or administration of dexrazoxane, an iron chelator reverses the anthracycline-induced mitochondrial iron overload and oxidative injury. It has been reported that the expression of TNF- $\alpha$ and IL- 6 in the myocardial tissue and H9C2 cells treated with DOX increased significantly (1, 198, 205-208). Taxane further inhibits mitophagy by interfering with the normal microtubular transport function in the cardiomyocytes $(26,153,198)$.

Unlike anthracyclines, trastuzumab induced left ventricular dysfunction (LVD) and congestive heart failure (CHF) are mostly reversible upon its discontinuation. At a molecular level, trastuzumab binds to the extracellular domain 4 of HER2 receptor, which prevents HER2 dimerization, activation and downstream signaling (190, 194-196). It may induce the occurrence of oxidative stress, which can also lead to the opening of MPTP and the activation of cell death pathways, leading to cardiac dysfunction $(192,209,210)$. There are reports that drugs that cause type II cardiotoxicity can also enhance anthracycline cardiotoxicity, such as azidothymidine and rosiglitazone (193, 198, 211). In addition, there are some antidepressants and excessive metal elements, such as cloflupine, cocaine, antimony, mercury and so on $(197,212)$.

\section{Mitochondrial Fission, Fusion and Poisoning}

Poisoning can change the mitochondrial dynamically regulated protein expression. On the one hand, poisoning induces the expression of MFN2 and OPA1 in the cardiac tissue, which increases the mitochondrial length and organelle aspect ratio and excessive mitochondrial fusion. As a result, the activity of mitochondrial respiratory chains is reduced, which leads to severe cell defects (213-215). On the other hand, poisoning promotes apoptosis by promoting DRP1 phosphorylation, subsequentially leading to the fission of mitochondria in cardiac cells (216).

\section{Mitophagy and Poisoning}

Doxorubicin (DOX), organophosphorus, nicotine, excessive alcohol, and other toxic substances can also inhibit the expression of Parkin, deteriorate the mitophagy ability of cardiac cells, damage mitochondria, and destroyed substances in cardiac cells will continue to accumulate, causing cardiac damage (26, 217, 218). Moreover, the decrease of mitophagy can lead to excessive ROS in cardiac cells, further promote the release of cytochrome $c$ and cysteine aspartate protease, disrupt the stability of mitochondria DNA, inhibit the activity of respiratory electron-transport chain, and reduce both oxygen utilization and consumption. It can even initiate mitochondrial apoptosis and induce mitochondrial damage (26, 88, 219-224). Parkin overexpression increases mitophagy, which aggravates cell death through poisoning. And, Parkin knockdown has the opposite effect $(225,226)$. DOX can also dysregulate the cytosolic and mitochondrial signaling axes, which leads to mitophagy destruction and arrhythmias, causing impaired mitochondrial clearance, the accumulation of dysfunctional mitochondria, ROS overload, and a lack of Adenosine triphosphate (ATP). Meanwhile, DOX can also phosphorylate BNIP3 and then inhibit mitophagy, which is closely related to the mitochondrial sirtuins (SIRT3-SIRT4) pathway (26, 27, 150, 206, 207, 221, $225,227,228)$. Recently, it was reported that excessive DOX can also significantly induce elevated insulin-like growth factorII receptor (IGF-IIR) expression, IGF-IIR induces myocardial hypertrophy and cardiomyocyte death in a paracrine/autocrine manner. Concurrently, IGF-IIR can further promote mitophagy by inducing Parkin expression and cause cardiac damage (28, 229, 230).

\section{THERAPEUTIC APPLICATION OF MITOCHONDRIAL DYNAMICS AND MITOPHAGY}

Mitochondrial dynamics and mitophagy play an important role in cardiotoxicity, so they can be regarded as potential therapeutic targets. Cardiotoxicity can be treated, or its progress can be delayed by promoting or inhibiting mitochondrial dynamics and mitophagy, thus maintaining the functional stability of mitochondria and reducing cell damage under the influence of injury factors (Table 1).

Hypoxia preconditioning induced FUNDC1-dependent activation of mitophagy and decreased I/R-induced cardiac injury (79). Shaftaside is a natural flavonoid. Shaftaside and MYLS22 can effectively inhibit the expression of DRP1 and OPA1 to inhibit mitochondrial fission and reduce the cardiotoxicity induced by hypoxia, oxidative stress, hyperglycemia and poisoning (231). In healthy and MIRI rat cardiomyocytes, $\mathrm{Zn}$ and salidroside can activate mitophagy by up-regulating the expression of PINK1/Parkin, clear damaged mitochondria, and maintain normal cardiac function (86, 232-234). Myocardial mitochondrial function adapts to stress during acute exercise and manifests as significant upregulation of the mitophagy-related protein BNIP3, which stimulates mitophagy and minimizes myocardial injury. Melatonin and acute exercise preconditioning can activate the expression of PINK1 and BNIP3, respectively, to enhance mitophagy and decreased ROS-induced cardiac injury (235-242). Metformin can inhibit mitochondrial fission by the activation of MFN1 and the inhibition of DRP1, which decreased hyperglycemia -induced cardiotoxicity (176, 243-247).

\section{CONCLUSIONS AND PROSPECTS}

Mitochondrial dynamics and mitophagy are decisive factors for maintaining the homeostasis of the cardiac cell environment 
TABLE 1 | Therapeutic application of mitochondrial dynamics and mitophagy.

\begin{tabular}{|c|c|c|c|c|}
\hline Injury factors & Key protein & Representative interventions & Mechanisms & Effects to cardiotoxicity \\
\hline Hypoxia & FUNDC1 & Hypoxia preconditioning & Mitophagy & Protection \\
\hline Hypoxia & DRP1 & Schaftoside & Fission & Protection \\
\hline OS & PINK1 & Zine, Melatonin & Mitophagy & Protection \\
\hline OS & BNIP3 & Acute exercise & Mitophagy & Protection \\
\hline OS & DRP1 & Melatonin & Fission & Protection \\
\hline Hyperglycemia & DRP1 & Metformin & Fission & Protection \\
\hline Hyperglycemia & MFN1 & Metformin & Fission & Protection \\
\hline Anthracyclines poisoning & BNIP3 & Acute exercise & Mitophagy & Protection \\
\hline Organophosphate poisoning & Parkin & Salidroside & Mitophagy & Protection \\
\hline Nicotine poisoning & OPA1 & MYLS22 & Fusion & Protection \\
\hline
\end{tabular}

and ensuring the normal function of the cardiac. Hypoxia, hyperglycemia, and oxidative stress mainly interfere with mitochondrial fission and mitophagy to cause cardiotoxicity, while poisoning mainly interferes with mitochondrial fusion and mitophagy to cause cardiotoxicity. In view of different injury factors, taking different representative interventions to maintain the normal mitochondrial dynamics and mitophagy is of great significance for the prevention and treatment of cardiotoxicity. However, whether different therapeutic effects can be achieved through different routes of administration requires further research. Therefore, the exploration, regulation, and monitoring of the balance point in mitochondrial dynamics is crucial for preventing external injury factors from inducing cardiotoxicity. However, at the advent, the specific mechanism of action of mitochondrial dynamics and mitophagy in the process of cardiotoxicity is yet to be established. Extensive empirical

\section{REFERENCES}

1. Varricchi G, Ameri P, Cadeddu C, Ghigo A, Madonna R, Marone G, et al. Antineoplastic drug-induced cardiotoxicity: a redox perspective. Front Physiol. (2018) 9:167. doi: 10.3389/fphys.2018.00167

2. Luo Y, Ma J, Lu W. The significance of mitochondrial dysfunction in cancer. Int J Mol Sci. (2020) 21:5598. doi: 10.3390/ijms21165598

3. Vasquez-Trincado C, Garcia-Carvajal I, Pennanen C, Parra V, Hill JA, Rothermel BA, et al. Mitochondrial dynamics, mitophagy and cardiovascular disease. J Physiol. (2016) 594:509-25. doi: 10.1113/JP271301

4. Lazarou M. Keeping the immune system in check: a role for mitophagy. Immunol Cell Biol. (2015) 93:3-10. doi: 10.1038/icb.2014.75

5. Galluzzi L, Vitale I, Aaronson SA, Abrams JM, Adam D, Agostinis $\mathrm{P}$, et al. Molecular mechanisms of cell death: recommendations of the nomenclature committee on cell death 2018. Cell Death Differ. (2018) 25:486-541. doi: 10.1038/s41418-017-0012-4

6. Appiah Kubi G, Pei D. Cell-penetrating and mitochondriontargeting molecules. Meth Enzymol. (2020) 641:31128. doi: 10.1016/bs.mie.2020.04.044

7. Bajpai P, Darra A, Agrawal A. Microbe-mitochondrion crosstalk and health: an emerging paradigm. Mitochondrion. (2018) 39:20-5. doi: 10.1016/j.mito.2017.08.008

8. Biner O, Schick T, Ganguin AA, von Ballmoos C. Towards a synthetic mitochondrion. Chimia. (2018) 72:291-6. doi: 10.2533/chimia.2018.291

9. Kuang S, Sun L, Zhang X, Liao X, Rees TW, Zeng L, et al. A mitochondrion-localized two-photon photosensitizer generating carbon studies are needed to study, confirm, and provide a theoretical basis for mitochondrial dynamics-induced cardiotoxicity, which would help prevent various causes of cardiotoxicity.

\section{AUTHOR CONTRIBUTIONS}

HS and YY contributed to conception and design of the study. YY wrote the first draft of the manuscript. All authors contributed to the article and approved the submitted version.

\section{FUNDING}

This study was funded by Science Foundation of Liaoning Education Department (FWZR2020012), 345 Talent Project of Shengjing Hospital, Science and Technology Department of Liaoning Province (2020JH2/10300126). radicals against hypoxic tumors. Angew Chem Int Ed Engl. (2020) 59:20697703. doi: $10.1002 /$ anie. 202009888

10. Roth KG, Mambetsariev I, Kulkarni P, Salgia R. The mitochondrion as an emerging therapeutic target in cancer. Trends Mol Med. (2020) 26:11934. doi: 10.1016/j.molmed.2019.06.009

11. Yang X, Zhang D, Li J, Ji W, Yang N, Gu S, et al. A mitochondriontargeting Mn(ii)-terpyridine complex for two-photon photodynamic therapy. Chem Commun. (2020) 56:9032-5. doi: 10.1039/D0CC0 $2051 \mathrm{~F}$

12. Zhuang Y, Li L, Feng L, Wang S, Su H, Liu H, et al. Mitochondriontargeted selenium nanoparticles enhance reactive oxygen species-mediated cell death. Nanoscale. (2020) 12:1389-96. doi: 10.1039/C9NR0 $9039 \mathrm{H}$

13. Hampl V, Cepička I, Eliáš $M$. Was the mitochondrion necessary to start eukaryogenesis? Trends Microbiol. (2019) 27:96-104. doi: 10.1016/j.tim.2018.10.005

14. Chan DC. Mitochondrial dynamics and its involvement in disease. Annu Rev Pathol. (2020) 15:23559. doi: 10.1146/annurev-pathmechdis-012419-032711

15. Zimorski V, Rauch C, van Hellemond JJ, Tielens AGM, Martin WF. The mitochondrion of euglena gracilis. Adv Exp Med Biol. (2017) 979:1937. doi: 10.1007/978-3-319-54910-1_2

16. Annesley SJ, Fisher PR. Mitochondria in health and disease. Cells. (2019) 8:680. doi: 10.3390/cells 8070680

17. Yang Y, Li T, Li Z, Liu N, Yan Y, Liu B. Role of mitophagy in cardiovascular disease. Aging Dis. (2020) 11:419-37. doi: 10.14336/AD.2019.0518 
18. Shah M, Chacko LA, Joseph JP, Ananthanarayanan V. Mitochondrial dynamics, positioning and function mediated by cytoskeletal interactions. Cell Mol Life Sci. (2021) doi: 10.1007/s00018-021-03762-5

19. Xian H, Liou YC. Functions of outer mitochondrial membrane proteins: mediating the crosstalk between mitochondrial dynamics and mitophagy. Cell Death Differ. (2021) 28:827-42. doi: 10.1038/s41418-020-00657-z

20. Fenton AR, Jongens TA, Holzbaur ELF. Mitochondrial dynamics: shaping and remodeling an organelle network. Curr Opin Cell Biol. (2021) 68:2836. doi: 10.1016/j.ceb.2020.08.014

21. Martinet W, Schrijvers DM, Timmermans JP, Bult H. Interactions between cell death induced by statins and 7-ketocholesterol in rabbit aorta smooth muscle cells. Br J Pharmacol. (2008) 154:1236-46. doi: 10.1038/bjp.2008.181

22. Morales CR, Pedrozo Z, Lavandero S, Hill JA. Oxidative stress and autophagy in cardiovascular homeostasis. Antioxid Redox Signal. (2014) 20:507-18. doi: 10.1089/ars.2013.5359

23. Davidson SM, Adameová A, Barile L, Cabrera-Fuentes HA, Lazou A, Pagliaro P, et al. Mitochondrial and mitochondrial-independent pathways of myocardial cell death during ischaemia and reperfusion injury. J Cell Mol Med. (2020) 24:3795-806. doi: 10.1111/jcmm.15127

24. Qiu Z, Ming H, Lei S, Zhou B, Zhao B, Yu Y, et al. Roles of HDAC3-orchestrated circadian clock gene oscillations in diabetic rats following myocardial ischaemia/reperfusion injury. Cell Death Dis. (2021) 12:43. doi: 10.1038/s41419-020-03295-y

25. Wang Y, Zhang C, Shen Z, Kou R, Xie K, Song F. Activation of PINK1-Parkin-dependent mitophagy in Tri-ortho-cresyl phosphate-treated Neuro2a cells. Chem Biol Int. (2019) 308:7079. doi: 10.1016/j.cbi.2019.05.025

26. Bartlett JJ, Trivedi PC, Pulinilkunnil T. Autophagic dysregulation in doxorubicin cardiomyopathy. J Mol Cell Cardiol. (2017) 104:1-8. doi: 10.1016/j.yjmcc.2017.01.007

27. Koleini N, Kardami E. Autophagy and mitophagy in the context of doxorubicin-induced cardiotoxicity. Oncotarget. (2017) 8:46663-80. doi: 10.18632/oncotarget.16944

28. Pandey S, Kuo W-W, Shen C-Y, Yeh Y-L, Ho T-J, Chen R-J, et al. Insulin-like growth factor II receptor- $\alpha$ is a novel stress-inducible contributor to cardiac damage underpinning doxorubicin-induced oxidative stress and perturbed mitochondrial autophagy. Am J Physiol Cell Physiol. (2019) 317:C23543. doi: 10.1152/ajpcell.00079.2019

29. Xin T, Lu C. Irisin activates opa1-induced mitophagy to protect cardiomyocytes against apoptosis following myocardial infarction. Aging. (2020) 12:4474-88. doi: 10.18632/aging.102899

30. Guan L, Che Z, Meng X, Yu Y, Li M, Yu Z, et al. MCU Upregulation contributes to myocardial ischemia-reperfusion injury through calpain/OPA-1-mediated mitochondrial fusion/mitophagy inhibition. J Cell Mol Med. (2019) 23:7830-43. doi: 10.1111/jcmm.14662

31. Wang S, Wang L, Qin X, Turdi S, Sun D, Culver B, et al. ALDH2 contributes to melatonin-induced protection against APP/PS1 mutation-prompted cardiac anomalies through cGAS-STING-TBK1mediated regulation of mitophagy. Sig Transd Targ Ther. (2020) 5:119. doi: 10.1038/s41392-020-0171-5

32. Hu Y, Wang X, Li Q, Pan Y, Xu L. Salvianolic acid B alleviates myocardial ischemic injury by promoting mitophagy and inhibiting activation of the NLRP3 inflammasome. Mol Med Rep. (2020) 22:5199208. doi: 10.3892/mmr.2020.11589

33. Chiao YA, Kolwicz SC, Basisty N, Gagnidze A, Zhang J, Gu H, et al. Rapamycin transiently induces mitochondrial remodeling to reprogram energy metabolism in old hearts. Aging. (2016) 8:31427. doi: 10.18632/aging.100881

34. Xie LL, Shi F, Tan Z, Li Y, Bode AM, Cao Y. Mitochondrial network structure homeostasis and cell death. Cancer Sci. (2018) 109:368694. doi: 10.1111/cas.13830

35. Bhargava P, Schnellmann RG. Mitochondrial energetics in the kidney. Nat Rev Nephrol. (2017) 13:629-46. doi: 10.1038/nrneph.2017.107

36. Chiurazzi M, Di Maro M, Cozzolino M, Colantuoni A. Mitochondrial dynamics and microglia as new targets in metabolism regulation. Int J Mol Sci. (2020) 21:3450. doi: 10.3390/ijms21103450

37. Ding M, Liu C, Shi R, Yu M, Zeng K, Kang J, et al. Mitochondrial fusion promoter restores mitochondrial dynamics balance and ameliorates diabetic cardiomyopathy in an optic atrophy 1-dependent way. Acta Physiol. (2020) 229:e13428. doi: 10.1111/apha.13428

38. Michurina SS, Stafeev IS, Menshikov MY, Parfyonova YV. Mitochondrial dynamics keep balance of nutrient combustion in thermogenic adipocytes. Mitochondrion. (2021) 59:157-68. doi: 10.1016/j.mito.2021.05.001

39. Simula L, Nazio F, Campello S. The mitochondrial dynamics in cancer and immune-surveillance. Semin Cancer Biol. (2017) 47:2942. doi: 10.1016/j.semcancer.2017.06.007

40. Zhong X, Cui P, Cai Y, Wang L, He X, Long P, et al. Mitochondrial dynamics is critical for the full pluripotency and embryonic developmental potential of pluripotent stem cells. Cell Metab. (2019) 29:979-92.e4. doi: 10.1016/j.cmet.2018.11.007

41. Serasinghe MN, Chipuk JE. Mitochondrial fission in human diseases. Handb Exp Pharmacol. (2017) 240:159-88. doi: 10.1007/164_2016_38

42. Wang Y, Liu HH, Cao YT, Zhang LL, Huang F, Yi C. The role of mitochondrial dynamics and mitophagy in carcinogenesis, metastasis and therapy. Front Cell Dev Biol. (2020) 8:413. doi: 10.3389/fcell.2020.00413

43. Houzelle A, Jörgensen JA, Schaart G, Daemen S, van Polanen N, Fealy $\mathrm{CE}$, et al. Human skeletal muscle mitochondrial dynamics in relation to oxidative capacity and insulin sensitivity. Diabetologia. (2021) 64:42436. doi: 10.1007/s00125-020-05335-w

44. Nomura R, Sato T, Sato Y, Medin JA, Kushimoto S, Yanagisawa T. Azidothymidine-triphosphate impairs mitochondrial dynamics by disrupting the quality control system. Redox Biol. (2017) 13:40717. doi: 10.1016/j.redox.2017.06.011

45. Lam HYP, Chen CC, Chen TT, Chang KC, Wu WJ, Yang TH, et al. Mitochondrial dynamics in angiostrongylus cantonensis-infected mouse brain. Parasitol Int. (2021) 80:102231. doi: 10.1016/j.parint.2020.102231

46. Zhu H, Toan S, Mui D, Zhou H. Mitochondrial quality surveillance as a therapeutic target in myocardial infarction. Acta Physiol. (2021) 231:e13590. doi: 10.1111/apha.13590

47. McLean FH, Campbell FM, Langston RF, Sergi D, Resch C, Grant C, et al. A high-fat diet induces rapid changes in the mouse hypothalamic proteome. Nutr Metab. (2019) 16:26. doi: 10.1186/s12986-019-0352-9

48. Lu Y, Chen L, Ye J, Chen C, Zhou Y, Li K, et al. Surgery/Anesthesia disturbs mitochondrial fission/fusion dynamics in the brain of aged mice with postoperative delirium. Aging. (2020) 12:844-65. doi: 10.18632/aging.102659

49. Li R, Toan S, Zhou H. Role of mitochondrial quality control in the pathogenesis of nonalcoholic fatty liver disease. Aging. (2020) 12:646785. doi: 10.18632/aging.102972

50. Liu X, Zhao X, Li X, Lv S, Ma R, Qi Y, et al. $\mathrm{PM}(2.5)$ triggered apoptosis in lung epithelial cells through the mitochondrial apoptotic way mediated by a ROS-DRP1-mitochondrial fission axis. J Hazard Mater. (2020) 397:122608. doi: 10.1016/j.jhazmat.2020.122608

51. Wang Z, White A, Wang X, Ko J, Choudhary G, Lange T, et al. Mitochondrial fission mediated cigarette smoke-induced pulmonary endothelial injury. Am J Respir Cell Mol Biol. (2020) 63:637-51. doi: 10.1165/rcmb.2020-0 $008 \mathrm{OC}$

52. Yu R, Lendahl $\mathrm{U}$, Nistér $\mathrm{M}$, Zhao J. Regulation of mammalian mitochondrial dynamics: opportunities and challenges. Front Endocrinol. (2020) 11:374. doi: 10.3389/fendo.2020.00374

53. Wu QR, Zheng DL, Liu PM, Yang H, Li LA, Kuang SJ, et al. High glucose induces Drp1-mediated mitochondrial fission via the orail calcium channel to participate in diabetic cardiomyocyte hypertrophy. Cell Death Dis. (2021) 12:216. doi: 10.1038/s41419-021-03502-4

54. Wu L, Kang Z, Qiao N, Wang C, Tang Z. Cu-induced mitochondrial dysfunction is mediated by abnormal mitochondrial fission through oxidative stress in primary chicken embryo hepatocytes. J Trace Elem Med Biol. (2021) 65:126721. doi: 10.1016/j.jtemb.2021.126721

55. Shang X, Zhang Y, Xu J, Li M, Wang X, Yu R. SRV2 promotes mitochondrial fission and Mst1-Drp1 signaling in LPS-induced septic cardiomyopathy. Aging. (2020) 12:1417-32. doi: 10.18632/aging.102691

56. Han H, Tan J, Wang R, Wan H, He Y, Yan X, et al. PINK1 phosphorylates $\operatorname{Drp1(S616)}$ to regulate mitophagy-independent mitochondrial dynamics. EMBO Rep. (2020) 21:e48686. doi: 10.15252/embr.201948686

57. Saotome M, Ikoma T, Hasan P, Maekawa Y. Cardiac insulin resistance in heart failure: the role of mitochondrial dynamics. Int J Mol Sci. (2019) 20:3552. doi: 10.3390/ijms20143552 
58. Han H, Li X, Guo Y, Zheng M, Xue T, Wang L. Plant sterol ester of $\alpha$-linolenic acid ameliorates high-fat diet-induced nonalcoholic fatty liver disease in mice: association with regulating mitochondrial dysfunction and oxidative stress via activating AMPK signaling. Food Funct. (2021) 12:217188. doi: 10.1039/D0FO02623A

59. Gao S, Hu J. Mitochondrial fusion: the machineries in and out. Trends Cell Biol. (2021) 31:62-74. doi: 10.1016/j.tcb.2020.09.008

60. Di Nottia M, Verrigni D, Torraco A, Rizza T, Bertini E, Carrozzo R. Mitochondrial dynamics: molecular mechanisms, related primary mitochondrial disorders and therapeutic approaches. Genes. (2021) 12:247. doi: 10.3390/genes12020247

61. Sessions DT, Kashatus DF. Mitochondrial dynamics in cancer stem cells. Cell Mol Life Sci. (2021) 78:3803-16. doi: 10.1007/s00018-021-03773-2

62. Wang L, Huang X, Dai T, Xie J, Lv QX, Hou Y, et al. The role of mitochondrial dynamics in the $\mathrm{TiO}(2)$ nanotube-accelerated osteogenic differentiation of MC3T3-E1 cells. Biochem Biophys Res Commun. (2021) 535:33-8. doi: 10.1016/j.bbrc.2020.12.025

63. Xiao Y, Chen W, Zhong Z, Ding L, Bai H, Chen $\mathrm{H}$, et al. Electroacupuncture preconditioning attenuates myocardial ischemiareperfusion injury by inhibiting mitophagy mediated by the mTORC1-ULK1-FUNDC1 pathway. Biomed Pharmacother. (2020) 127:110148. doi: 10.1016/j.biopha.2020.110148

64. Yu W, Gao B, Li N, Wang J, Qiu C, Zhang G, et al. Sirt3 deficiency exacerbates diabetic cardiac dysfunction: role of Foxo3A-Parkin-mediated mitophagy. Biochim Biophys Acta Mol Basis Dis. (2017) 1863:197383. doi: 10.1016/j.bbadis.2016.10.021

65. Gottlieb RA, Andres AM, Sin J, Taylor DP. Untangling autophagy measurements: all fluxed up. Circ Res. (2015) 116:504-14. doi: 10.1161/CIRCRESAHA.116.303787

66. Yang X, Pan W, Xu G, Chen L. Mitophagy: a crucial modulator in the pathogenesis of chronic diseases. Clin Chim Acta. (2020) 502:24554. doi: 10.1016/j.cca.2019.11.008

67. Bi W, Jia J, Pang R, Nie C, Han J, Ding Z, et al. Thyroid hormone postconditioning protects hearts from ischemia/reperfusion through reinforcing mitophagy. Biomed Pharmacother. (2019) 118:109220. doi: 10.1016/j.biopha.2019.109220

68. Li G, Yang J, Yang C, Zhu M, Jin Y, McNutt MA, et al. PTENalpha regulates mitophagy and maintains mitochondrial quality control. Autophagy. (2018) 14:1742-60. doi: 10.1080/15548627.2018.1489477

69. Yang KC, Ma X, Liu H, Murphy J, Barger PM, Mann DL, et al. Tumor necrosis factor receptor-associated factor 2 mediates mitochondrial autophagy. Circ Heart Fail. (2015) 8:75-87. doi: 10.1161/CIRCHEARTFAILURE.114. 001635

70. Feng Y, Zhao J, Hou H, Zhang H, Jiao Y, Wang J, et al. WDR26 promotes mitophagy of cardiomyocytes induced by hypoxia through Parkin translocation. Acta Biochim Biophys Sin. (2016) 48:1075-84. doi: 10.1093/abbs/gmw104

71. Huang C, Andres AM, Ratliff EP, Hernandez G, Lee P, Gottlieb RA. Preconditioning involves selective mitophagy mediated by Parkin and p62/SQSTM1. PLoS ONE. (2011) 6:e20975. doi: 10.1371/journal.pone.0020975

72. Piquereau J, Godin R, Deschenes S, Bessi VL, Mofarrahi M, Hussain $\mathrm{SN}$, et al. Protective role of PARK2/Parkin in sepsis-induced cardiac contractile and mitochondrial dysfunction. Autophagy. (2013) 9:183751. doi: 10.4161 /auto. 26502

73. Li J, Shi W, Zhang J, Ren L. To explore the protective mechanism of PTEN-Induced Kinase 1 (PINK1)/parkin mitophagy-mediated extract of periplaneta americana on lipopolysaccharide-induced cardiomyocyte injury. Med Sci Monitor. (2019) 25:1383-91. doi: 10.12659/MSM.912980

74. Yang CN, Kok SH, Wang HW, Chang JZ, Lai EH, Shun CT, et al. Simvastatin alleviates bone resorption in apical periodontitis possibly by inhibition of mitophagy-related osteoblast apoptosis. Int Endod J. (2019) 52:67688. doi: 10.1111/iej.13055

75. Monier S, Samadi M, Prunet C, Denance M, Laubriet A, Athias $\mathrm{A}$, et al. Impairment of the cytotoxic and oxidative activities of 7 $\beta$-hydroxycholesterol and 7-ketocholesterol by esterification with oleate. Biochem Biophys Res Commun. (2003) 303:814-24. doi: 10.1016/S0006-291X(03)00412-1
76. Lazarova D, Semkova S, Zlateva G, Tatsuya H, Aoki I, Bakalova R. Quantum sensors to track total redox-status and oxidative stress in cells and tissues using electron-paramagnetic resonance, magnetic resonance imaging, optical imaging. Anal Chem. (2021) 93:2828-37. doi: 10.1021/acs.analchem.0c04116

77. Andres AM, Hernandez G, Lee P, Huang C, Ratliff EP, Sin J, et al. Mitophagy is required for acute cardioprotection by simvastatin. Antioxid Redox Signal. (2014) 21:1960-73. doi: 10.1089/ars.2013.5416

78. Gottlieb RA, Pourpirali S. Lost in translation: miRNAs and mRNAs in ischemic preconditioning and ischemia/reperfusion injury. $\mathrm{J} \mathrm{Mol}$ Cell Cardiol. (2016) 95:70-7. doi: 10.1016/j.yjmcc.2015.11.011

79. Zhang W, Siraj S, Zhang R, Chen Q. Mitophagy receptor FUNDC1 regulates mitochondrial homeostasis and protects the heart from I/R injury. Autophagy. (2017) 13:1080-1. doi: 10.1080/15548627.2017.1300224

80. Cao S, Sun Y, Wang W, Wang B, Zhang Q, Pan C, et al. Poly (ADP-ribose) polymerase inhibition protects against myocardial ischaemia/reperfusion injury via suppressing mitophagy. J Cell Mol Med. (2019) 23:6897906. doi: 10.1111/jcmm.14573

81. Feng Y, Madungwe NB, da Cruz Junho CV, Bopassa JC. Activation of $\mathrm{G}$ protein-coupled oestrogen receptor 1 at the onset of reperfusion protects the myocardium against ischemia/reperfusion injury by reducing mitochondrial dysfunction and mitophagy. Br J Pharmacol. (2017) 174:4329-44. doi: 10.1111/bph.14033

82. Lu W, Sun J, Yoon JS, Zhang Y, Zheng L, Murphy E, et al. Mitochondrial protein PGAM5 regulates mitophagic protection against cell necroptosis. PLoS ONE. (2016) 11:e0147792. doi: 10.1371/journal.pone.0147792

83. Fan $\mathrm{H}, \mathrm{He} \mathrm{Z}$, Huang $\mathrm{H}$, Zhuang $\mathrm{H}$, Liu H, Liu X, et al. Mitochondrial quality control in cardiomyocytes: a critical role in the progression of cardiovascular diseases. Front Physiol. (2020) 11:252. doi: 10.3389/fphys.2020.00252

84. Xiao D, Chang W, Ding W, Wang Y, Fa H, Wang J. Enhanced mitophagy mediated by the YAP/Parkin pathway protects against DOX-induced cardiotoxicity. Toxicol Lett. (2020) 330:96-107. doi: 10.1016/j.toxlet.2020.05.015

85. Xiong W, Hua J, Liu Z, Cai W, Bai Y, Zhan Q, et al. PTEN induced putative kinase 1 (PINK1) alleviates angiotensin II-induced cardiac injury by ameliorating mitochondrial dysfunction. Int J Cardiol. (2018) 266:198205. doi: 10.1016/j.ijcard.2018.03.054

86. Bian X, Teng T, Zhao H, Qin J, Qiao Z, Sun Y, et al. Zinc prevents mitochondrial superoxide generation by inducing mitophagy in the setting of hypoxia/reoxygenation in cardiac cells. Free Radic Res. (2018) 52:8091. doi: 10.1080/10715762.2017.1414949

87. Lee Y, Kwon I, Jang Y, Cosio-Lima L, Barrington P. Endurance exercise attenuates doxorubicin-induced cardiotoxicity. Med Sci Sports Exercise. (2020) 52:25-36. doi: 10.1249/MSS.0000000000002094

88. Zhou H, Zhu P, Wang J, Zhu H, Ren J, Chen Y. Pathogenesis of cardiac ischemia reperfusion injury is associated with $\mathrm{CK} 2 \alpha$-disturbed mitochondrial homeostasis via suppression of FUNDC1-related mitophagy. Cell Death Different. (2018) 25:1080-93. doi: 10.1038/s41418-0180086-7

89. Zhu N, Li J, Li Y, Zhang Y, Du Q, Hao P, et al. Berberine protects against simulated ischemia/reperfusion injury-induced H9C2 cardiomyocytes apoptosis In Vitro and myocardial ischemia/reperfusion-induced apoptosis In Vivo by regulating the mitophagy-mediated HIF-1alpha/BNIP3 pathway. Front Pharmacol. (2020) 11:367. doi: 10.3389/fphar.2020. 00367

90. Kubli DA, Gustafsson ÅB. Unbreak my heart: targeting mitochondrial autophagy in diabetic cardiomyopathy. Antioxid Redox Sig. (2015) 22:152744. doi: 10.1089/ars.2015.6322

91. Jin $\mathrm{Q}, \mathrm{Li} \mathrm{R}, \mathrm{Hu} \mathrm{N}, \mathrm{Xin} \mathrm{T}, \mathrm{Zhu} \mathrm{P}, \mathrm{Hu} \mathrm{S}$, et al. DUSP1 alleviates cardiac ischemia/reperfusion injury by suppressing the Mff-required mitochondrial fission and Bnip3-related mitophagy via the JNK pathways. Redox Biol. (2018) 14:576-87. doi: 10.1016/j.redox.2017.11.004

92. Li W, Yin L, Sun $\mathrm{X}$, Wu J, Dong $\mathrm{Z}, \mathrm{Hu} \mathrm{K}$, et al. Alpha-lipoic acid protects against pressure overload-induced heart failure via ALDH2-dependent Nrf1-FUNDC1 signaling. Cell Death Dis. (2020) 11:599. doi: 10.1038/s41419-020-02805-2

93. Zhang W, Chen C, Wang J, Liu L, He Y, Chen Q. Mitophagy in cardiomyocytes and in platelets: a major mechanism of 
cardioprotection against ischemia/reperfusion injury. Physiology. (2018) 33:86-98. doi: 10.1152/physiol.00030.2017

94. Fontecha-Barriuso M, Martin-Sanchez D, Martinez-Moreno JM, Monsalve M, Ramos AM, Sanchez-Niño MD, et al. The role of PGC-1 $\alpha$ and mitochondrial biogenesis in kidney diseases. Biomolecules. (2020) 10:347. doi: 10.3390/biom10020347

95. Li Y, Feng YF, Liu XT, Li YC, Zhu HM, Sun MR, et al. Songorine promotes cardiac mitochondrial biogenesis via Nrf2 induction during sepsis. Redox Biol. (2021) 38:101771. doi: 10.1016/j.redox.2020.101771

96. Liu L, Li Y, Wang J, Zhang D, Wu H, Li W, et al. Mitophagy receptor FUNDC1 is regulated by PGC-1 $1 / \mathrm{NRF} 1$ to fine tune mitochondrial homeostasis. EMBO Rep. (2021) 22:e50629. doi: 10.15252/embr.202050629

97. Nishida Y, Nawaz A, Kado T, Takikawa A, Igarashi Y, Onogi Y, et al. Astaxanthin stimulates mitochondrial biogenesis in insulin resistant muscle via activation of AMPK pathway. J Cachexia Sarcopenia Muscle. (2020) 11:241-258. doi: 10.1002/jcsm.12530

98. Bishop DJ, Botella J, Genders AJ, Lee MJ, Saner NJ, Kuang J, et al. High-intensity exercise and mitochondrial biogenesis: current controversies and future research directions. Physiology. (2019) 34:56-70. doi: 10.1152/physiol.00038.2018

99. Fanibunda SE, Deb S, Maniyadath B, Tiwari P, Ghai U, Gupta S, et al. Serotonin regulates mitochondrial biogenesis and function in rodent cortical neurons via the 5-HT(2A) receptor and SIRT1-PGC-1 $\alpha$ axis. Proc Natl Acad Sci USA. (2019) 116:11028-37. doi: 10.1073/pnas.1821332116

100. Krämer L, Groh C, Herrmann JM. The proteasome: friend and foe of mitochondrial biogenesis. FEBS Lett. (2021) 595:122338. doi: $10.1002 / 1873-3468.14010$

101. Bouchez C, Devin A. Mitochondrial biogenesis and mitochondrial reactive oxygen species (ROS): a complex relationship regulated by the cAMP/PKA signaling pathway. Cells. (2019) 8:287. doi: 10.3390/cells8040287

102. English AM, Schuler MH, Xiao T, Kornmann B, Shaw JM, Hughes AL. ER-mitochondria contacts promote mitochondrial-derived compartment biogenesis. J Cell Biol. (2020) 219:e202002144. doi: 10.1083/jcb.202002144

103. Blanco FJ, Fernández-Moreno M. Mitochondrial biogenesis: a potential therapeutic target for osteoarthritis. Osteoarthr Cartil. (2020) 28:10036. doi: $10.1016 /$ j.joca.2020.03.018

104. Sheremet NL, Andreeva NA, Shmel'kova MS, Tsigankova PG. [Mitochondrial biogenesis in hereditary optic neuropathies]. Vestn Oftalmol. (2019) 135:85-91. doi: 10.17116/oftalma201913505185

105. Tang JX, Thompson K, Taylor RW, Oláhová M. Mitochondrial OXPHOS biogenesis: co-regulation of protein synthesis, import, assembly pathways. Int J Mol Sci. (2020) 21:3820. doi: 10.3390/ijms21113820

106. Simmons EC, Scholpa NE, Schnellmann RG. Mitochondrial biogenesis as a therapeutic target for traumatic and neurodegenerative CNS diseases. Exp Neurol. (2020) 329:113309. doi: 10.1016/j.expneurol.2020.113309

107. Brunello E, Fusi L, Ghisleni A, Park-Holohan SJ, Ovejero JG, Narayanan T, et al. Myosin filament-based regulation of the dynamics of contraction in heart muscle. Proc Natl Acad Sci USA. (2020) 117:8177-86. doi: 10.1073/pnas.1920632117

108. Corbin EA, Vite A, Peyster EG, Bhoopalam M, Brandimarto J, Wang $\mathrm{X}$, et al. Tunable and reversible substrate stiffness reveals a dynamic mechanosensitivity of cardiomyocytes. ACS Appl Mater Interfaces. (2019) 11:20603-14. doi: 10.1021/acsami.9b02446

109. Datta Chaudhuri R, Banik A, Mandal B, Sarkar S. Cardiac-specific overexpression of HIF-1 $\alpha$ during acute myocardial infarction ameliorates cardiomyocyte apoptosis via differential regulation of hypoxia-inducible pro-apoptotic and anti-oxidative genes. Biochem Biophys Res Commun. (2021) 537:100-8. doi: 10.1016/j.bbrc.2020.12.084

110. Dias PP, Capila RF, do Couto NF, Estrada D, Gadelha FR, Radi $\mathrm{R}$, et al. Cardiomyocyte oxidants production may signal to $\mathrm{T}$. Cruzi intracellular development. PLoS Negl Trop Dis. (2017) 11:e0005852. doi: 10.1371/journal.pntd.0005852

111. Haque ZK, Wang DZ. How cardiomyocytes sense pathophysiological stresses for cardiac remodeling. Cell Mol Life Sci. (2017) 74:9831000. doi: 10.1007/s00018-016-2373-0

112. Huang TH, Yip HK, Sun CK, Chen YL, Yang CC, Lee FY. P-cresyl sulfate causes mitochondrial hyperfusion in $\mathrm{H} 9 \mathrm{C} 2$ cardiomyoblasts. J Cell Mol Med. (2020) 24:8379-90. doi: $10.1111 /$ jcmm.15303
113. Kang H, Liu J, Sun A, Liu X, Fan Y, Deng X. Vascular smooth muscle cell glycocalyx mediates shear stress-induced contractile responses via a Rho kinase (ROCK)-myosin light chain phosphatase (MLCP) pathway. Sci Rep. (2017) 7:42092. doi: 10.1038/srep42092

114. Ling SSM, Chen YT, Wang J, Richards AM, Liew OW. Ankyrin repeat domain 1 protein: a functionally pleiotropic protein with cardiac biomarker potential. Int J Mol Sci. (2017) 18. doi: 10.3390/ijms18071362

115. Zhou J, Xi C, Wang W, Fu X, Jinqiang L, Qiu Y, et al. Triptolide-induced oxidative stress involved with Nrf2 contribute to cardiomyocyte apoptosis through mitochondrial dependent pathways. Toxicol Lett. (2014) 230:45466. doi: 10.1016/j.toxlet.2014.08.017

116. Zhou H, Zhang Y, Hu S, Shi C, Zhu P, Ma Q, et al. Melatonin protects cardiac microvasculature against ischemia/reperfusion injury via suppression of mitochondrial fission-VDAC1-HK2-mPTP-mitophagy axis. J Pineal Res. (2017) 63:e12413. doi: 10.1111/jpi.12413

117. Yu W, Sun S, Xu H, Li C, Ren J, Zhang Y. TBC1D15/RAB7regulated mitochondria-lysosome interaction confers cardioprotection against acute myocardial infarction-induced cardiac injury. Theranostics. (2020) 10:11244-63. doi: 10.7150/thno.46883

118. Farías JG, Molina VM, Carrasco RA, Zepeda AB, Figueroa E, Letelier $\mathrm{P}$, et al. Antioxidant therapeutic strategies for cardiovascular conditions associated with oxidative stress. Nutrients. (2017) 9:966. doi: 10.3390/nu90 90966

119. Mancilla TR, Iskra B, Aune GJ. Doxorubicin-induced cardiomyopathy in children. Compr Physiol. (2019) 9:905-31. doi: 10.1002/cphy.c180017

120. Bar-Yosef T, Damri O, Agam G. Dual role of autophagy in diseases of the central nervous system. Front Cell Neurosci. (2019) 13:196. doi: 10.3389/fncel.2019.00196

121. Axelrod CL, King WT, Davuluri G, Noland RC, Hall J, Hull M, et al. BAM15-mediated mitochondrial uncoupling protects against obesity and improves glycemic control. EMBO Mol Med. (2020) 12:e12088. doi: 10.15252/emmm.202012088

122. Blignaut M, Espach Y, van Vuuren M, Dhanabalan K, Huisamen B. Revisiting the cardiotoxic effect of chloroquine. Cardiovasc Drugs Ther. (2019) 33:111. doi: 10.1007/s10557-018-06847-9

123. Dai J, Liang K, Zhao S, Jia W, Liu Y, Wu H, et al. Chemoproteomics reveals baicalin activates hepatic CPT1 to ameliorate diet-induced obesity and hepatic steatosis. Proc Natl Acad Sci USA. (2018) 115:E5896905. doi: 10.1073/pnas.1801745115

124. Araya J, Tsubouchi K, Sato N, Ito S, Minagawa S, Hara H, et al. PRKNregulated mitophagy and cellular senescence during COPD pathogenesis. Autophagy. (2019) 15:510-26. doi: 10.1080/15548627.2018.1532259

125. Barish R, Lynce F, Unger K, Barac A. Management of cardiovascular disease in women with breast cancer. Circulation. (2019) 139:111020. doi: 10.1161/CIRCULATIONAHA.118.039371

126. Findlay SG, Gill JH, Plummer R, DeSantis C, Plummer C. Chronic cardiovascular toxicity in the older oncology patient population. J Geriatr Oncol. (2019) 10:685-9. doi: 10.1016/j.jgo.2019.01.018

127. Kaboré EG, Guenancia C, Vaz-Luis I, Di Meglio A, Pistilli B, Coutant C, et al. Association of body mass index and cardiotoxicity related to anthracyclines and trastuzumab in early breast cancer: French CANTO cohort study. PLoS Med. (2019) 16:e1002989. doi: 10.1371/journal.pmed.1002989

128. Kalkhoran SB, Hernandez-Resendiz S, Ong SG, Ramachandra CJA, Hausenloy DJ. Mitochondrial shaping proteins as novel treatment targets for cardiomyopathies. Cond Med. (2020) 3:216-26.

129. Kosalka P, Johnson C, Turek M, Sulpher J, Law A, Botros J, et al. Effect of obesity, dyslipidemia, and diabetes on trastuzumab-related cardiotoxicity in breast cancer. Curr Oncol. (2019) 26:e314-21. doi: 10.3747/co. 26.4823

130. Tan L, Su X, Li X, Li H, Hu B. Correlation of HER2 codon 655 polymorphism with cardiotoxicity risk in Chinese HER2-positive breast cancer patients undergoing epirubicin/cyclophosphamide followed by docetaxel plus trastuzumab adjuvant chemotherapy. Int J Clin Exp Pathol. (2020) 13:286-94.

131. Yao RQ, Ren C, Xia ZF, Yao YM. Organelle-specific autophagy in inflammatory diseases: a potential therapeutic target underlying the quality control of multiple organelles. Autophagy. (2021) 17:385-401. doi: 10.1080/15548627.2020.1725377 
132. Xie Q, Li S, Gao Y, Jin L, Dai C, Song J. Ergosterol attenuates isoproterenolinduced myocardial cardiotoxicity. Cardiovasc Toxicol. (2020) 20:5006. doi: 10.1007/s12012-020-09574-6

133. FrangeŽ R, Šuput D, Molgó J, Benoit E. Ostreolysin a/pleurotolysin b and equinatoxins: structure, function and pathophysiological effects of these pore-forming proteins. Toxins. (2017) 9:128. doi: 10.3390/toxins 9040128

134. Zhou H, Fu LX, Li L, Chen YY, Zhu HQ, Zhou JL, et al. The epigallocatechin gallate derivative Y6 reduces the cardiotoxicity and enhances the efficacy of daunorubicin against human hepatocellular carcinoma by inhibiting carbonyl reductase 1 expression. J Ethnopharmacol. (2020) 261:113118. doi: 10.1016/j.jep.2020.113118

135. Yang F, Zhao LN, Sun Y, Chen Z. Levosimendan as a new force in the treatment of sepsis-induced cardiomyopathy: mechanism and clinical application. J Int Med Res. (2019) 47:1817-28. doi: 10.1177/0300060519837103

136. Song Y, Xu C, Liu J, Li Y, Wang H, Shan D, et al. Heterodimerization with 5$\mathrm{HT}(2 \mathrm{~B}) \mathrm{R}$ is indispensable for $\beta(2) \mathrm{AR}-$ Mediated cardioprotection. Circ Res. (2021) 128:262-77. doi: 10.1161/CIRCRESAHA.120.317011

137. Yu X, Ruan Y, Shen T, Qiu Q, Yan M, Sun S, et al. Dexrazoxane protects cardiomyocyte from doxorubicin-induced apoptosis by modulating miR-175p. Biomed Res Int. (2020) 2020:5107193. doi: 10.1155/2020/5107193

138. Cypher AD, Consiglio J, Bagatto B. Hypoxia exacerbates the cardiotoxic effect of the polycyclic aromatic hydrocarbon, phenanthrene in Danio rerio. Chemosphere. (2017) 183:574-81. doi: 10.1016/j.chemosphere.2017.05.109

139. Zhao Y, Wang B, Zhang J, He D, Zhang Q, Pan C, et al. ALDH2 (aldehyde dehydrogenase 2) protects against hypoxia-induced pulmonary hypertension. Arterioscler Thromb Vasc Biol. (2019) 39:2303-19. doi: 10.1161/ATVBAHA.119.312946

140. Zhang D, Liu Y, Tang Y, Wang X, Li Z, Li R, et al. Increased mitochondrial fission is critical for hypoxia-induced pancreatic beta cell death. PLOS ONE. (2018) 13:e0197266. doi: 10.1371/journal.pone.0197266

141. Nishimura A, Shimauchi T, Tanaka T, Shimoda K, Toyama T, Kitajima $\mathrm{N}$, et al. Hypoxia-induced interaction of filamin with Drp1 causes mitochondrial hyperfission-associated myocardial senescence. Sci Signal. (2018) 11:eaat5185. doi: 10.1126/scisignal.aat5185

142. Kuang Y, Ma K, Zhou C, Ding P, Zhu Y, Chen Q, et al. Structural basis for the phosphorylation of FUNDC1 LIR as a molecular switch of mitophagy. Autophagy. (2016) 12:2363-73. doi: 10.1080/15548627.2016.1238552

143. Lv M, Wang C, Li F, Peng J, Wen B, Gong Q, et al. Structural insights into the recognition of phosphorylated FUNDC1 by LC3B in mitophagy. Protein Cell. (2016) 8:25-38. doi: 10.1007/s13238-016-0328-8

144. Hao P, Liu Y, Guo H, Zhang Z, Chen Q, Hao G, et al. Prolylcarboxypeptidase mitigates myocardial ischemia/reperfusion injury by stabilizing mitophagy. Front Cell Dev Biol. (2020) 8:584933. doi: 10.3389/fcell.2020.584933

145. Zhou $\mathrm{H}, \mathrm{Li} \mathrm{D}, \mathrm{Zhu} \mathrm{P}, \mathrm{Hu} \mathrm{S}, \mathrm{Hu} \mathrm{N}, \mathrm{Ma} \mathrm{S}$, et al. Melatonin suppresses platelet activation and function against cardiac ischemia/reperfusion injury via PPAR $\gamma /$ FUNDC1/mitophagy pathways. J Pineal Res. (2017) 63:e12438. doi: 10.1111/jpi.12438

146. Paradies G, Paradies V, Ruggiero FM, Petrosillo G. Mitochondrial bioenergetics and cardiolipin alterations in myocardial ischemia-reperfusion injury: implications for pharmacological cardioprotection. Am J Physiol Heart Circ Physiol. (2018) 315:H1341-52. doi: 10.1152/ajpheart.00028.2018

147. Hernandez-Resendiz S, Prunier F, Girao H, Dorn G, Hausenloy DJ, E-Action CC. Targeting mitochondrial fusion and fission proteins for cardioprotection. J Cell Mol Med. (2020) 24:657185. doi: $10.1111 / \mathrm{jcmm} .15384$

148. Songbo M, Lang H, Xinyong C, Bin X, Ping Z, Liang S. Oxidative stress injury in doxorubicin-induced cardiotoxicity. Toxicol Lett. (2019) 307:418. doi: 10.1016/j.toxlet.2019.02.013

149. Chen T, Deng Z, Zhao R, Shen H, Li W. SYKT alleviates doxorubicininduced cardiotoxicity via modulating ROS-Mediated p53 and MAPK signal pathways. Evid Based Compl Alternat Med. (2018) 2018:2581031. doi: 10.1155/2018/2581031

150. He L, Liu F, Li J. Mitochondrial sirtuins and Doxorubicininduced cardiotoxicity. Cardiovasc Toxicol. (2021) 21:17991. doi: 10.1007/s12012-020-09626-x
151. Kurauchi K, Nishikawa T, Miyahara E, Okamoto Y, Kawano Y. Role of metabolites of cyclophosphamide in cardiotoxicity. BMC Res Notes. (2017) 10:406. doi: 10.1186/s13104-017-2726-2

152. Long G, Chen H, Wu M, Li Y, Gao L, Huang S, et al. Antianemia drug roxadustat (FG-4592) protects against doxorubicin-induced cardiotoxicity by targeting antiapoptotic and antioxidative pathways. Front Pharmacol. (2020) 11:1191. doi: 10.3389/fphar.2020.01191

153. Lu J, Li J, Hu Y, Guo Z, Sun D, Wang P, et al. Chrysophanol protects against doxorubicin-induced cardiotoxicity by suppressing cellular PARylation. Acta Pharm Sin B. (2019) 9:782-93. doi: 10.1016/j.apsb.2018.10.008

154. Russo M, Guida F, Paparo L, Trinchese G, Aitoro R, Avagliano C, et al. The novel butyrate derivative phenylalanine-butyramide protects from doxorubicin-induced cardiotoxicity. Eur J Heart Fail. (2019) 21:51928. doi: 10.1002/ejhf.1439

155. Wei S, Ma W, Li X, Jiang C, Sun T, Li Y, et al. Involvement of ROS/NLRP3 inflammasome signaling pathway in doxorubicin-induced cardiotoxicity. Cardiovasc Toxicol. (2020) 20:507-19. doi: 10.1007/s12012-020-09576-4

156. Yarmohammadi F, Rezaee R, Karimi G. Natural compounds against doxorubicin-induced cardiotoxicity: a review on the involvement of Nrf2/ARE signaling pathway. Phytother Res. (2021) 35 1163-75. doi: 10.1002/ptr.6882

157. Zhao L, Qi Y, Xu L, Tao X, Han X, Yin L, et al. MicroRNA-140-5p aggravates doxorubicin-induced cardiotoxicity by promoting myocardial oxidative stress via targeting Nrf2 and Sirt2. Redox Biol. (2018) 15:28496. doi: 10.1016/j.redox.2017.12.013

158. Barnes PJ. Oxidative stress-based therapeutics in COPD. Redox Biol. (2020) 33:101544. doi: 10.1016/j.redox.2020.101544

159. Cano Sanchez M, Lancel S, Boulanger E, Neviere R. Targeting oxidative stress and mitochondrial dysfunction in the treatment of impaired wound healing: a systematic review. Antioxidants. (2018) 7:98. doi: 10.3390/antiox7080098

160. Datta S, Cano M, Ebrahimi K, Wang L, Handa JT. The impact of oxidative stress and inflammation on RPE degeneration in non-neovascular AMD. Prog Retin Eye Res. (2017) 60:201-18. doi: 10.1016/j.preteyeres.2017.03.002

161. Yin J, Guo J, Zhang Q, Cui L, Zhang L, Zhang T, et al. Doxorubicininduced mitophagy and mitochondrial damage is associated with dysregulation of the PINK1/parkin pathway. Toxicol In Vitro. (2018) 51:1-10. doi: 10.1016/j.tiv.2018.05.001

162. Penna C, Perrelli MG, Pagliaro P. Mitochondrial pathways, permeability transition pore, and redox signaling in cardioprotection: therapeutic implications. Antioxid Redox Signal. (2013) 18:55699. doi: 10.1089/ars.2011.4459

163. Chen Z, Wu D, Li L, Chen L. Apelin/APJ system: a novel therapeutic target for myocardial ischemia/reperfusion injury. DNA Cell Biol. (2016) 35:766-75. doi: 10.1089/dna.2016.3391

164. Tian Y, Lv W, Lu C, Zhao X, Zhang C, Song H. LATS2 promotes cardiomyocyte $\mathrm{H} 9 \mathrm{C} 2$ cells apoptosis via the Prx3Mfn2-mitophagy pathways. J Recept Signal Transduct Res. (2019) 39:470-8. doi: 10.1080/10799893.2019.1701031

165. Gottlieb RA, Mentzer Jr RM, Linton PJ. Impaired mitophagy at the heart of injury. Autophagy. (2011) 7:1573-4. doi: 10.4161/auto.7.12.18175

166. Miller BA, Cheung JY. TRPM2 protects against tissue damage following oxidative stress and ischaemia-reperfusion. J Physiol. (2016) 594:418191. doi: 10.1113/JP270934

167. Tang L, Li Y-p, Hu J, Chen A-h, Mo Y. Dexpramipexole attenuates myocardial ischemia/reperfusion injury through upregulation of mitophagy. Eur J Pharmacol. (2021) 899:173962. doi: 10.1016/j.ejphar.2021.173962

168. Wu MY, Yiang GT, Liao WT, Tsai AP, Cheng YL, Cheng PW, et al. Current mechanistic concepts in ischemia and reperfusion injury. Cell Physiol Biochem. (2018) 46:1650-67. doi: 10.1159/000489241

169. Tang W, Lin D, Chen M, Li Z, Zhang W, Hu W, et al. PTENmediated mitophagy and APE1 overexpression protects against cardiac hypoxia/reoxygenation injury. In Vitro Cell Dev Biol Animal. (2019) 55:7418. doi: 10.1007/s11626-019-00389-6

170. Zhou H, Zhu P, Guo J, Hu N, Wang S, Li D, et al. Ripk3 induces mitochondrial apoptosis via inhibition of FUNDC1 mitophagy in cardiac IR injury. Redox Biology. (2017) 13::498-507. doi: 10.1016/j.redox.2017.07.007 
171. Wu H, Ye M, Liu D, Yang J, Ding Jw, Zhang J, et al. UCP2 protect the heart from myocardial ischemia/reperfusion injury via induction of mitochondrial autophagy. J Cell Biochem. (2019) 120:15455-66. doi: 10.1002/jcb.28812

172. Lee TL, Lee M-H, Chen Y-C, Lee Y-C, Lai T-C, et al. Vitamin D attenuates ischemia/reperfusion-induced cardiac injury by reducing mitochondrial fission and mitophagy. Front Pharmacol. (2020) 11:604700. doi: 10.3389/fphar.2020.604700

173. Li Q, Yu Z, Xiao D, Wang Y, Zhao L, An Y, et al. Baicalein inhibits mitochondrial apoptosis induced by oxidative stress in cardiomyocytes by stabilizing MARCH5 expression. J Cell Mol Med. (2020) 24:204051. doi: $10.1111 /$ jcmm. 14903

174. Su B-C, Hsu P-L, Mo F-E. CCN1 triggers adaptive autophagy in cardiomyocytes to curb its apoptotic activities. J Cell Commun Sig. (2019) 14:93-100. doi: 10.1007/s12079-019-00534-6

175. Chaurasia SS, Lim RR, Parikh BH, Wey YS, Tun BB, Wong TY, et al. The NLRP3 inflammasome may contribute to pathologic neovascularization in the advanced stages of diabetic retinopathy. Sci Rep. (2018) 8:2847. doi: 10.1038/s41598-018-21198-z

176. Ding S, Xu S, Ma Y, Liu G, Jang H, Fang J. Modulatory mechanisms of the NLRP3 inflammasomes in diabetes. Biomolecules. (2019) 9:850. doi: 10.3390/biom9120850

177. Hou Y, Lin S, Qiu J, Sun W, Dong M, Xiang Y, et al. NLRP3 inflammasome negatively regulates podocyte autophagy in diabetic nephropathy. Biochem Biophys Res Commun. (2020) 521:791-8. doi: 10.1016/j.bbrc.2019. 10.194

178. Li DX, Wang CN, Wang Y, Ye CL, Jiang L, Zhu XY, et al. NLRP3 inflammasome-dependent pyroptosis and apoptosis in hippocampus neurons mediates depressive-like behavior in diabetic mice. Behav Brain Res. (2020) 391:112684. doi: 10.1016/j.bbr.2020.112684

179. Wan Z, Fan Y, Liu X, Xue J, Han Z, Zhu C, et al. NLRP3 inflammasome promotes diabetes-induced endothelial inflammation and atherosclerosis. Diabetes Metab Syndr Obes. (2019) 12:1931-42. doi: 10.2147/DMSO.S2 22053

180. Wang J, Shen X, Liu J, Chen W, Wu F, Wu W, et al. High glucose mediates NLRP3 inflammasome activation via upregulation of ELF3 expression. Cell Death Dis. (2020) 11:383. doi: 10.1038/s41419-020-2598-6

181. Hao Y, Liu HM, Wei X, Gong X, Lu ZY, Huang ZH. Diallyl trisulfide attenuates hyperglycemia-induced endothelial apoptosis by inhibition of Drp1-mediated mitochondrial fission. Acta Diabetol. (2019) 56:117789. doi: 10.1007/s00592-019-01366-X

182. Wu G, Xiong Q, Wei X, Wang Y, Hu X, He G, et al. Mitochondrial unfolded protein response gene CLPP changes mitochondrial dynamics and affects mitochondrial function. PeerJ. (2019) 7:e7209. doi: 10.7717/peerj.7209

183. Zheng F, Jia B, Dong F, Liu L, Rasul F, He J, et al. Glucose starvation induces mitochondrial fragmentation depending on the dynamin GTPase Dnm1/Drp1 in fission yeast. J Biol Chem. (2019) 294:1772534. doi: 10.1074/jbc.RA119.010185

184. Rohrbach S, Aslam M, Niemann B, Schulz R. Impact of caloric restriction on myocardial ischaemia/reperfusion injury and new therapeutic options to mimic its effects. $\mathrm{Br} J$ Pharmacol. (2014) 171:2964-92. doi: 10.1111/bph.12650

185. Yu LM, Dong X, Xue XD, Xu S, Zhang X, Xu YL, et al. Melatonin attenuates diabetic cardiomyopathy and reduces myocardial vulnerability to ischemiareperfusion injury by improving mitochondrial quality control: Role of SIRT6. J Pineal Res. (2020) 70:e12698. doi: 10.1111/jpi.12698

186. Kobayashi S, Zhao F, Zhang Z, Kobayashi T, Huang Y, Shi B, et al. Mitochondrial fission and mitophagy coordinately restrict high glucose toxicity in cardiomyocytes. Front Physiol. (2020) 11:604069. doi: 10.3389/fphys.2020.604069

187. Nishida K, Otsu K. Sterile inflammation and degradation systems in heart failure. Circ J. (2017) 81:622-8. doi: 10.1253/circj.CJ-17-0261

188. Hu L, Ding M, Tang D, Gao E, Li C, Wang K, et al. Targeting mitochondrial dynamics by regulating Mfn2 for therapeutic intervention in diabetic cardiomyopathy. Theranostics. (2019) 9:3687-706. doi: 10.7150/thno. 33684

189. Xu X, Kobayashi S, Chen K, Timm D, Volden P, Huang Y, et al. Diminished autophagy limits cardiac injury in mouse models of type
1 diabetes. J Biol Chem. (2013) 288:18077-92. doi: 10.1074/jbc.M113. 474650

190. Ewer MS, Ewer SM. Cardiotoxicity of anticancer treatments. Nat Rev Cardiol. (2015) 12:547-58. doi: 10.1038/nrcardio.2015.65

191. Ferdinandy P, Baczkó I, Bencsik P, Giricz Z, Görbe A, Pacher P, et al. Definition of hidden drug cardiotoxicity: paradigm change in cardiac safety testing and its clinical implications. Eur Heart J. (2019) 40:177177. doi: 10.1093/eurheartj/ehy365

192. Jain D, Aronow W. Cardiotoxicity of cancer chemotherapy in clinical practice. Hosp Pract 1995. (2019) 47:6-15. doi: 10.1080/21548331.2018.1530831

193. Nicolazzi MA, Carnicelli A, Fuorlo M, Scaldaferri A, Masetti R, Landolfi R, et al. Anthracycline and trastuzumab-induced cardiotoxicity in breast cancer. Eur Rev Med Pharmacol Sci. (2018) 22:2175-85. doi: 10.26355/eurrev_201804_14752

194. Bhagat A, Kleinerman ES. Anthracycline-induced cardiotoxicity: causes, mechanisms, and prevention. Adv Exp Med Biol. (2020) 1257:18192. doi: 10.1007/978-3-030-43032-0_15

195. Cardinale D, Colombo A, Bacchiani G, Tedeschi I, Meroni CA, Veglia F, et al. Early detection of anthracycline cardiotoxicity and improvement with heart failure therapy. Circulation. (2015) 131:19818. doi: 10.1161/CIRCULATIONAHA.114.013777

196. Curigliano G, Cardinale D, Dent S, Criscitiello C, Aseyev O, Lenihan $\mathrm{D}$, et al. Cardiotoxicity of anticancer treatments: epidemiology, detection, and management. CA Cancer J Clin. (2016) 66:309-25. doi: 10.3322/caac. 21341

197. Shabalala S, Muller CJF, Louw J, Johnson R. Polyphenols, autophagy and doxorubicin-induced cardiotoxicity. Life Sci. (2017) 180:160-70. doi: 10.1016/j.lfs.2017.05.003

198. Varga ZV, Ferdinandy P, Liaudet L, Pacher P. Drug-induced mitochondrial dysfunction and cardiotoxicity. Am J Physiol Heart Circ Physiol. (2015) 309:H1453-67. doi: 10.1152/ajpheart.00554.2015

199. Burridge PW, Li YF, Matsa E, Wu H, Ong SG, Sharma A, et al. Human induced pluripotent stem cell-derived cardiomyocytes recapitulate the predilection of breast cancer patients to doxorubicin-induced cardiotoxicity. Nat Med. (2016) 22:547-56. doi: 10.1038/nm.4087

200. Gorini S, De Angelis A, Berrino L, Malara N, Rosano G, Ferraro E. Chemotherapeutic drugs and mitochondrial dysfunction: focus on doxorubicin, trastuzumab, and sunitinib. Oxid Med Cell Longev. (2018) 2018:7582730. doi: 10.1155/2018/7582730

201. Hantson P. Mechanisms of toxic cardiomyopathy. Clin Toxicol. (2019) 57:1-9. doi: 10.1080/15563650.2018.1497172

202. Henriksen PA. Anthracycline cardiotoxicity: an update on mechanisms, monitoring and prevention. Heart. (2018) 104:97177. doi: 10.1136/heartjnl-2017-312103

203. Prathumsap N, Shinlapawittayatorn K, Chattipakorn SC, Chattipakorn N. Effects of doxorubicin on the heart: from molecular mechanisms to intervention strategies. Eur J Pharmacol. (2020) 866:172818. doi: 10.1016/j.ejphar.2019.172818

204. Tadokoro T, Ikeda M, Ide T, Deguchi H, Ikeda S, Okabe K, et al. Mitochondria-dependent ferroptosis plays a pivotal role in doxorubicin cardiotoxicity. JCI Insight. (2020) 5:e132747. doi: 10.1172/jci.insight.1 32747

205. Timm KN, Tyler DJ. The role of AMPK activation for cardioprotection in doxorubicin-induced cardiotoxicity. Cardiovasc Drugs Ther. (2020) 34:25569. doi: 10.1007/s10557-020-06941-x

206. Wallace KB, Sardão VA, Oliveira PJ. Mitochondrial determinants of doxorubicin-induced cardiomyopathy. Circ Res. (2020) 126:926-41. doi: 10.1161/CIRCRESAHA.119.314681

207. Wang P, Wang L, Lu J, Hu Y, Wang Q, Li Z, et al. SESN2 protects against doxorubicin-induced cardiomyopathy via rescuing mitophagy and improving mitochondrial function. J Mol Cell Cardiol. (2019) 133:12537. doi: 10.1016/j.yjmcc.2019.06.005

208. Wenningmann N, Knapp M, Ande A, Vaidya TR, Ait-Oudhia S. Insights into doxorubicin-induced cardiotoxicity: molecular mechanisms, preventive strategies, early monitoring. Mol Pharmacol. (2019) 96:21932. doi: $10.1124 / \mathrm{mol} .119 .115725$ 
209. Herrmann J. Adverse cardiac effects of cancer therapies: cardiotoxicity and arrhythmia. Nat Rev Cardiol. (2020) 17:474502. doi: 10.1038/s41569-020-0348-1

210. Jerusalem G, Lancellotti P, Kim SB. HER2+ breast cancer treatment and cardiotoxicity: monitoring and management. Breast Cancer Res Treat. (2019) 177:237-50. doi: 10.1007/s10549-019-05303-y

211. Zakaria ZZ, Benslimane FM, Nasrallah GK, Shurbaji S, Younes NN, Mraiche $\mathrm{F}$, et al. Using zebrafish for investigating the molecular mechanisms of drug-induced cardiotoxicity. Biomed Res Int. (2018) 2018:1642684. doi: 10.1155/2018/1642684

212. Rudy Y. In silico pipeline for drug cardiotoxicity assessment. Circ Res. (2020) 126:965-7. doi: 10.1161/CIRCRESAHA.120.316901

213. Abdullah CS, Alam S, Aishwarya R, Miriyala S, Bhuiyan MAN, Panchatcharam $M$, et al. Doxorubicin-induced cardiomyopathy associated with inhibition of autophagic degradation process and defects in mitochondrial respiration. Sci Rep. (2019) 9(1). doi: 10.1038/s41598-018-37862-3

214. Zhou L, Li R, Liu C, Sun T, Htet Aung LH, Chen C, et al. Foxo3a inhibits mitochondrial fission and protects against doxorubicin-induced cardiotoxicity by suppressing MIEF2. Free Radic Biol Med. (2017) 104:36070. doi: 10.1016/j.freeradbiomed.2017.01.037

215. Pillai VB, Kanwal A, Fang YH, Sharp WW, Samant S, Arbiser J, et al. Honokiol, an activator of Sirtuin-3 (SIRT3) preserves mitochondria and protects the heart from doxorubicin-induced cardiomyopathy in mice. Oncotarget. (2017) 8:34082-98. doi: 10.18632/oncotarget. 16133

216. Du J, Hang P, Pan Y, Feng B, Zheng Y, Chen T, et al. Inhibition of miR-23a attenuates doxorubicin-induced mitochondria-dependent cardiomyocyte apoptosis by targeting the PGC-1 $\alpha /$ Drp1 pathway. Toxicol Appl Pharmacol. (2019) 369:73-81. doi: 10.1016/j.taap.2019.02.016

217. Jia G, Meng Z, Liu C, Ma X, Gao J, Liu J, et al. Nicotine induces cardiac toxicity through blocking mitophagic clearance in young adult rat. Life Sciences. (2020) 257:118084. doi: 10.1016/j.lfs.2020.118084

218. Wang S, Ren J. Role of autophagy and regulatory mechanisms in alcoholic cardiomyopathy. Bio Biophys Acta. (2018) 1864:20039. doi: 10.1016/j.bbadis.2018.03.016

219. Saito T, Nah J, Oka SI, Mukai R, Monden Y, Maejima Y, et al. An alternative mitophagy pathway mediated by Rab9 protects the heart against ischemia. J Clin Invest. (2019) 129:802-19. doi: 10.1172/JCI122035

220. Zhang X, Li Z-L, Eirin A, Ebrahimi B, Pawar AS, Zhu X-Y, et al. Cardiac metabolic alterations in hypertensive obese pigs. Hypertension. (2015) 66:430-6. doi: 10.1161/HYPERTENSIONAHA.115.05478

221. Mancilla TR, Davis LR, Aune GJ. Doxorubicin-induced p53 interferes with mitophagy in cardiac fibroblasts. PLoS ONE. (2020) 15:e0238856. doi: 10.1371/journal.pone.0238856

222. Gharanei M, Hussain A, Janneh O, Maddock H. Attenuation of doxorubicininduced cardiotoxicity by mdivi-1: a mitochondrial division/mitophagy inhibitor. PLoS ONE. (2013) 8:e77713. doi: 10.1371/journal.pone.00 77713

223. Nordgren KKS, Wallace KB. Disruption of the Keap1/Nrf2-antioxidant response system after chronic doxorubicin exposure In Vivo. Cardiovasc Toxicol. (2020) 20:557-70. doi: 10.1007/s12012-020-0 9581-7

224. Dhingra A, Jayas R, Afshar P, Guberman M, Maddaford G, Gerstein J, et al. Ellagic acid antagonizes Bnip3-mediated mitochondrial injury and necrotic cell death of cardiac myocytes. Free Radic Biol Med. (2017) 112:41122. doi: 10.1016/j.freeradbiomed.2017.08.010

225. Catanzaro MP, Weiner A, Kaminaris A, Li C, Cai F, Zhao F, et al. Doxorubicin-induced cardiomyocyte death is mediated by unchecked mitochondrial fission and mitophagy. FASEB J. (2019) 33:11096-108. doi: 10.1096/fj.201802663R

226. Yang $\mathrm{M}$, Wang $\mathrm{S}, \mathrm{Fu} \mathrm{S}$, Wu NN, Xu X, Sun $\mathrm{S}$, et al. Deletion of the E3 ubiquitin ligase, Parkin, exacerbates chronic alcohol intakeinduced cardiomyopathy through an ambral-dependent mechanism. Bri J Pharmacol. (2021) 178:964-82. doi: 10.1111/bph.15340

227. Wang $\mathrm{P}$, Lan R, Guo Z, Cai S, Wang J, Wang Q, et al. Histone demethylase JMJD3 mediated doxorubicin-induced cardiomyopathy by suppressing SESN2 expression. Front Cell Dev Biol. (2020) 8:548605. doi: 10.3389/fcell.2020.548605

228. Liu X, Zhang S, An L, Wu J, Hu X, Lai S, et al. Loss of Rubicon ameliorates doxorubicin-induced cardiotoxicity through enhancement of mitochondrial quality. Int J Cardiol. (2019) 296:129-35. doi: 10.1016/j.ijcard.2019. 07.074

229. Huang CY, Kuo WW, Ho TJ, Chiang SF, Pai PY, Lin JY, et al. Rab9dependent autophagy is required for the IGF-IIR triggering mitophagy to eliminate damaged mitochondria. J Cell Physiol. (2018) 233:708091. doi: $10.1002 /$ jcp. 26346

230. Huang C-Y, Lai C-H, Kuo C-H, Chiang S-F, Pai P-Y, Lin J-Y, et al, Inhibition of ERK-Drp1 signaling and mitochondria fragmentation alleviates IGF-IIR-induced mitochondria dysfunction during heart failure. J Mol Cell Cardiol. (2018) 122:58-68. doi: 10.1016/j.yjmcc.2018. 08.006

231. Zhou K, Wu J, Chen J, Zhou Y, Chen X, Wu Q, et al. Schaftoside ameliorates oxygen glucose deprivation-induced inflammation associated with the TLR4/Myd88/Drp1-related mitochondrial fission in BV2 microglia cells. J Pharmacol Sci. (2019) 139:15-22. doi: 10.1016/j.jphs.2018. 10.012

232. Gu C, Li L, Huang Y, Qian D, Liu W, Zhang C, et al. Salidroside ameliorates mitochondria-dependent neuronal apoptosis after spinal cord ischemia-reperfusion injury partially through inhibiting oxidative stress and promoting mitophagy. Oxid Med Cell Longev. (2020) 2020:3549704. doi: 10.1155/2020/3549704

233. Li R, Chen J. Salidroside protects dopaminergic neurons by enhancing PINK1/parkin-mediated mitophagy. Oxid Med Cell Longev. (2019) 2019:9341018. doi: 10.1155/2019/9341018

234. Zhang Z, Xu T, Chen J, Shao Z, Wang K, Yan Y, et al. Parkinmediated mitophagy as a potential therapeutic target for intervertebral disc degeneration. Cell Death Dis. (2018) 9:980. doi: 10.1038/s41419-0181024-9

235. Yuan Y, Pan SS. Parkin mediates mitophagy to participate in cardioprotection induced by late exercise preconditioning but bnip3 does not. J Cardiovasc Pharmacol. (2018) 71:30316. doi: $10.1097 /$ FJC. 0000000000000572

236. Li H, Miao W, Ma J, Xv Z, Bo H, Li J, et al. Acute exercise-induced mitochondrial stress triggers an inflammatory response in the myocardium via NLRP3 inflammasome activation with mitophagy. Oxid Med Cell Longev. (2016) 2016:1987149. doi: 10.1155/2016/1987149

237. Cao S, Shrestha S, Li J, Yu X, Chen J, Yan F, et al. Melatonin-mediated mitophagy protects against early brain injury after subarachnoid hemorrhage through inhibition of NLRP3 inflammasome activation. Sci Rep. (2017) 7:2417. doi: 10.1038/s41598-017-02679-z

238. Dhanabalan K, Mzezewa S, Huisamen B, Lochner A. Mitochondrial oxidative phosphorylation function and mitophagy in ischaemic/reperfused hearts from control and high-fat diet rats: effects of long-term melatonin treatment. Cardiovasc Drugs Ther. (2020) 34:799-811. doi: 10.1007/s10557-020-0 6997-9

239. Han YS, Kim SM, Lee JH, Jung SK, Noh H, Lee SH. Melatonin protects chronic kidney disease mesenchymal stem cells against senescence via $\operatorname{Pr} \mathrm{P}(\mathrm{C})$-dependent enhancement of the mitochondrial function. J Pineal Res. (2019) 66:e12535. doi: 10.1111/jpi.12535

240. Kang JW, Hong JM, Lee SM. Melatonin enhances mitophagy and mitochondrial biogenesis in rats with carbon tetrachloride-induced liver fibrosis. J Pineal Res. (2016) 60:383-93. doi: 10.1111/jpi.12319

241. Liu Y, Yan J, Sun C, Li G, Li S, Zhang L, et al. Ameliorating mitochondrial dysfunction restores carbon ion-induced cognitive deficits via co-activation of NRF2 and PINK1 signaling pathway. Redox Biol. (2018) 17:14357. doi: 10.1016/j.redox.2018.04.012

242. Onphachanh X, Lee HJ, Lim JR, Jung YH, Kim JS, Chae CW, et al. Enhancement of high glucose-induced PINK1 expression by melatonin stimulates neuronal cell survival: involvement of $\operatorname{MT}(2)$ /Akt/NF-kB pathway. J Pineal Res. (2017) 63:e12427. doi: 10.1111/jpi. 12427

243. Wang Q, Zhang M, Torres G, Wu S, Ouyang C, Xie Z, et al. Metformin suppresses diabetes-accelerated atherosclerosis via the 
inhibition of drp1-mediated mitochondrial fission. Diabetes. (2017) 66:193-205. doi: 10.2337/db16-0915

244. de Marañón AM, Canet F, Abad-Jiménez Z, Jover A, Morillas C, Rocha $\mathrm{M}$, et al. Does metformin modulate mitochondrial dynamics and function in type 2 diabetic patients? Antioxid Redox Signal. (2021) 35:37785. doi: $10.1089 /$ ars. 2021.0019

245. Hu Y, Chen H, Zhang L, Lin X, Li X, Zhuang H, et al. The AMPKMFN2 axis regulates MAM dynamics and autophagy induced by energy stresses. Autophagy. (2021) 17:1142-56. doi: 10.1080/15548627.2020.1 749490

246. Izzo A, Nitti M, Mollo N, Paladino S, Procaccini C, Faicchia D, et al. Metformin restores the mitochondrial network and reverses mitochondrial dysfunction in down syndrome cells. Hum Mol Genet. (2017) 26:105669. doi: $10.1093 / \mathrm{hmg} / \mathrm{ddx} 016$

247. Mollo N, Nitti M, Zerillo L, Faicchia D, Micillo T, Accarino R, et al. Pioglitazone improves mitochondrial organization and bioenergetics in down syndrome cells. Front Genet. (2019) 10:606. doi: 10.3389/fgene.2019. 00606
Conflict of Interest: The authors declare that the research was conducted in the absence of any commercial or financial relationships that could be construed as a potential conflict of interest.

Publisher's Note: All claims expressed in this article are solely those of the authors and do not necessarily represent those of their affiliated organizations, or those of the publisher, the editors and the reviewers. Any product that may be evaluated in this article, or claim that may be made by its manufacturer, is not guaranteed or endorsed by the publisher.

Copyright (C) 2021 Yin and Shen. This is an open-access article distributed under the terms of the Creative Commons Attribution License (CC BY). The use, distribution or reproduction in other forums is permitted, provided the original author(s) and the copyright owner(s) are credited and that the original publication in this journal is cited, in accordance with accepted academic practice. No use, distribution or reproduction is permitted which does not comply with these terms. 